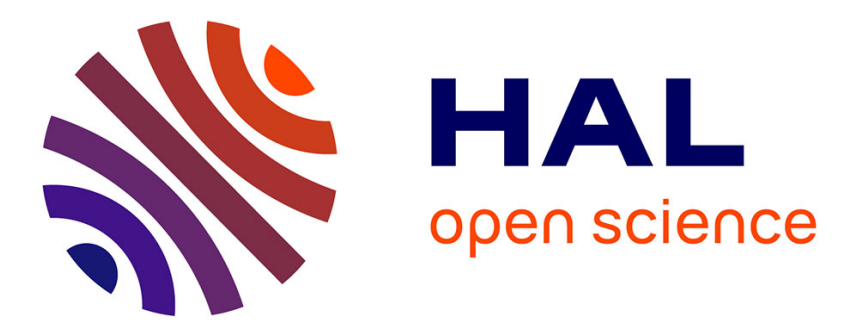

\title{
Functionalized Aromatic Dicarboxylate Ligands in Uranyl-Organic Assemblies: The Cases of Carboxycinnamate and 1,2-/1,3-Phenylenedioxydiacetate
}

Pierre Thuéry, Youssef Atoini, Jack Harrowfield

\section{To cite this version:}

Pierre Thuéry, Youssef Atoini, Jack Harrowfield. Functionalized Aromatic Dicarboxylate Ligands in Uranyl-Organic Assemblies: The Cases of Carboxycinnamate and 1,2-/1,3-Phenylenedioxydiacetate. Inorganic Chemistry, In press, 59, pp.2923-2936. 10.1021/acs.inorgchem.9b03273 . cea-02485715

\section{HAL Id: cea-02485715 https://hal-cea.archives-ouvertes.fr/cea-02485715}

Submitted on 20 Feb 2020

HAL is a multi-disciplinary open access archive for the deposit and dissemination of scientific research documents, whether they are published or not. The documents may come from teaching and research institutions in France or abroad, or from public or private research centers.
L'archive ouverte pluridisciplinaire HAL, est destinée au dépôt et à la diffusion de documents scientifiques de niveau recherche, publiés ou non, émanant des établissements d'enseignement et de recherche français ou étrangers, des laboratoires publics ou privés. 


\title{
Functionalized Aromatic Dicarboxylate Ligands in Uranyl-Organic Assemblies: the Cases of Carboxycinnamate and 1,2-/1,3-Phenylenedioxydiacetate
}

\author{
Pierre Thuéry, ${ }^{* \dagger}{ }^{\dagger}$ Youssef Atoini ${ }^{\ddagger}$ and Jack Harrowfield*, \\ $\dagger^{\dagger}$ NIMBE, CEA, CNRS, Université Paris-Saclay, CEA Saclay, 91191 Gif-sur-Yvette, France \\ ISIS, Université de Strasbourg, 8 allée Gaspard Monge, 67083 Strasbourg, France
}

\begin{abstract}
Carboxycinnamic acid $\left(\mathrm{ccnH}_{2}\right)$ and the isomeric 1,2- and 1,3-phenylenedioxydiacetic acids (1,2and 1,3-pddaH ${ }_{2}$ ) have been used to synthesize eight uranyl ion complexes under solvo-hydrothermal conditions. In the four complexes $\left[\mathrm{PPh}_{4}\right]_{2}\left[\mathrm{UO}_{2}(\mathrm{ccn})\left(\mathrm{NO}_{3}\right)\right]_{2}(\mathbf{1}),\left[\mathrm{PPh}_{4}\right]_{2}\left[\mathrm{UO}_{2}(\mathrm{ccn})(\mathrm{dibf})\right]_{2}(\mathbf{2}),\left[\mathrm{UO}_{2}(\mathrm{ccn})(\mathrm{bipy})\right]_{2}(\mathbf{3})$, and $\left[\mathrm{Ni}\left(R, S-\mathrm{Me}_{6} \mathrm{cyclam}\right)\right]\left[\mathrm{UO}_{2}(\mathrm{ccn})(\mathrm{HCOO})\right]_{2}(4)$, the $\mathrm{ccn}^{2-}$ dianion retains a nearly planar geometry, which favors the formation of the centrosymmetric $\left[\mathrm{UO}_{2}(\mathrm{ccn})\right]_{2}$ dimeric unit. Additional terminal ligands, either neutral (bipy = 2,2'-bipyridine) or anionic (nitrate, dibf $^{-}=1,3$-dihydro-3-oxo-1-isobenzofuranacetate, and formate, the two latter formed in situ) complete the uranyl coordination sphere, leading in all cases to discrete, dinuclear species. Sodium(I) bonding to the carboxylate/ether $\mathrm{O}_{4}$ site of the 1,2-pdda ${ }^{2-}$ dianion in the two complexes $\left[\mathrm{UO}_{2} \mathrm{Na}(1,2-\right.$ pdda) $(\mathrm{OH})]$ (5) and $\left[\left(\mathrm{UO}_{2}\right)_{2} \mathrm{Na}_{2}(1,2 \text {-pdda })_{2}\left(\mathrm{C}_{2} \mathrm{O}_{4}\right)\right]$ (6) results in this ligand being planar. Further lateral coordination to uranyl and sodium bonding to a uranyl oxo group allow formation of heterometallic diperiodic networks containing monoperiodic uranyl-only subunits. In the absence of $\mathrm{Na}^{+}$cations, 1,2-pdda ${ }^{2-}$ adopts a conformation in which one carboxylate group is tilted out of the ligand plane in $\left[\mathrm{UO}_{2}(1,2 \text {-pdda })_{2} \mathrm{Ni}\right.$ (cyclam)] (7), and diaxial carboxylato bonding to nickel(II) unites uranyl-only monoperiodic subunits into a diperiodic network. The 1,3-pdda ${ }^{2-}$ ligand in $\left[\mathrm{UO}_{2}(1,3-\mathrm{pdda})\left(\mathrm{H}_{2} \mathrm{O}\right)\right](\mathbf{8})$ is also non-planar with one tilted carboxylate group, and the bridging bidentate nature of both carboxylate groups allows formation of a triperiodic framework in which both metal and ligand are four-coordinated nodes. While the emission spectra of complexes $\mathbf{1}$ and $\mathbf{5}$ display the vibronic progression considered typical of uranyl ion, those of complexes $\mathbf{2 ,} \mathbf{4}$ and $\mathbf{8}$ show broad emission bands which in the case of complex 4 completely replace the uranyl emissions and which appear to be ligand-centred. The low energy of these broad bands can be rationalized in terms of the close association of certain ligand pairs within the structures.
\end{abstract}




\section{INTRODUCTION}

Among the multitude of ligands used in the synthesis of uranyl-organic species, ${ }^{1-5}$ those possessing a rigid platform bearing "acetate" (carboxymethyl) arms are particularly appealing due to the variety of geometries, convergent or divergent, they are able to adopt, while not being as completely flexible as purely aliphatic molecules can be. The simplest such rigid skeleton is the phenyl group, and both its di- and triacetate derivatives have given original uranyl ioncontaining coordination polymers of varying periodicity, ${ }^{6,7}$ while the equally rigid but bulkier adamantyl skeleton has proven well adapted to the formation of both polymeric assemblies and polynuclear closed species. ${ }^{8}$ Going beyond acetate substituents by lengthening the arms bearing the carboxylate groups would allow for larger separation of the bonding sites, but at the expense of increased flexibility, except if the inserted parts were to be themselves of limited mobility. An example of such a ligand is the commercially available 2-carboxycinnamic acid $\left(\mathrm{ccnH}_{2}\right.$, Scheme 1), where conjugation of the alkene unit with the ring is expected to favour their coplanarity, limiting the ligand to two conformations with rather different separations of their carboxylate units (one like that of the very rigid 1,7-naphthalenedicarboxylate, a ligand for which no uranyl ion complex has been characterized). Other commercially available extended diacetates where the insertion of an oxygen atom as the extension might be expected to have more subtle conformational influences, are the 1,2- and 1,3-phenylenedioxydiacetic acids (or catechol- and resorcinol-O, $O^{\prime}$-diacetic acids, denoted 1,2- and 1,3-pdda $\mathrm{H}_{2}$ and shown in Scheme 1). 2-Carboxycinnamate is a moderately common ligand, with only 23 crystal structures of metal ion complexes reported in the Cambridge Structural Database (CSD, version 5.40),,${ }^{9,10}$ none of them with an actinide cation, but 1,2- and 1,3-phenylenedioxydiacetates are somewhat commoner, with 72 and 36 structures reported, respectively. In particular, two uranyl ion complexes with 1,2-pdda ${ }^{2-}$ are known, [UO $\left.\mathrm{U}_{2}(1,2-\mathrm{pdda})\left(\mathrm{H}_{2} \mathrm{O}\right)\right]$ and 
$\left[\mathrm{H}_{2} \mathrm{DABCO}\right]\left[\left(\mathrm{UO}_{2}\right)_{2}(1,2-\text { pdda })_{3}\right] \cdot 1.5 \mathrm{H}_{2} \mathrm{O}(\mathrm{DABCO}=$ 1,4-diazabicyclo[2.2.2]octane $)$, which both crystallize as monoperiodic coordination polymers, the latter with a tube-like geometry. ${ }^{11}$ We have now synthesized four uranyl ion complexes with $\mathrm{ccn}^{2-}$, three with 1,2-pdda ${ }^{2-}$, and one with 1,3-pdda ${ }^{2-}$, which have been characterized by their crystal structure and uranyl emission spectrum in the solid state. While all complexes with $\mathrm{ccn}^{2-}$, whether neutral or anionic, crystallize as zero-periodic, dinuclear species, all those with 1,2-pdda ${ }^{2-}$, including additional $\mathrm{Na}^{+}$or $\mathrm{Ni}^{2+}$ cations, are diperiodic, and that with $1,3-\mathrm{pdda}^{2-}$ is triperiodic. Of additional interest are the chemical roles played by the extending groups beyond their conformational influences.<smiles>O=C(O)/C=C/c1ccccc1C(=O)O</smiles>

$\mathrm{ccnH}_{2}$<smiles>O=C(O)COc1ccccc1OCC(=O)O</smiles>

1,2-pdda $\mathrm{H}_{2}$<smiles>O=C(O)COc1cccc(OCC(=O)O)c1</smiles>

1,3-pddaH $\mathrm{H}_{2}$

Scheme 1. The Functionalized Aromatic Dicarboxylic Acids Used in this Study

\section{EXPERIMENTAL SECTION}

Syntheses. Caution! Uranium is a radioactive and chemically toxic element, and uranium-containing samples must be handled with suitable care and protection. 
$\mathrm{UO}_{2}\left(\mathrm{NO}_{3}\right)_{2} \cdot 6 \mathrm{H}_{2} \mathrm{O}$ (depleted uranium, R. P. Normapur, 99\%), was purchased from Prolabo. 2-Carboxycinnamic acid, and 1,2- and 1,3-phenylenedioxydiacetic acids were from Aldrich, while 2,2'-bipyridine was from Fluka. [Ni(cyclam $\left.)\left(\mathrm{NO}_{3}\right)_{2}\right]$ and $[\mathrm{Ni}(R, S$ $\mathrm{Me}_{6}$ cyclam $)\left(\mathrm{NO}_{3}\right)_{2}$ ] were synthesized as previously reported. ${ }^{12}$ Elemental analyses were performed by MEDAC Ltd. at Chobham, UK. For all syntheses, the mixtures in demineralized water/organic solvent were placed in $10 \mathrm{~mL}$ tightly closed glass vessels and heated at $140{ }^{\circ} \mathrm{C}$ under autogenous pressure. In the cases in which the yield was low, it has been checked that it could not be significantly increased with longer reaction times.

$\left[\mathrm{PPh}_{4}\right]_{2}\left[\mathrm{UO}_{2}(\mathrm{ccn})\left(\mathrm{NO}_{3}\right)\right]_{2} \quad$ (1). 2-Carboxycinnamic acid $(20 \mathrm{mg}, 0.10 \mathrm{mmol})$, $\mathrm{UO}_{2}\left(\mathrm{NO}_{3}\right)_{2} \cdot 6 \mathrm{H}_{2} \mathrm{O}(35 \mathrm{mg}, 0.07 \mathrm{mmol})$, and $\mathrm{PPh}_{4} \mathrm{Br}(42 \mathrm{mg}, 0.10 \mathrm{mmol})$ were dissolved in water $(0.7 \mathrm{~mL})$ and acetonitrile $(0.2 \mathrm{~mL})$. Yellow crystals of complex 1 were obtained in low yield within two weeks.

$\left[\mathrm{PPh}_{4}\right]_{2}\left[\mathrm{UO}_{2}(\mathrm{ccn})(\mathrm{dibf})\right]_{2}$ (2). 2-Carboxycinnamic acid $(20 \mathrm{mg}, 0.10 \mathrm{mmol})$, $\mathrm{UO}_{2}\left(\mathrm{NO}_{3}\right)_{2} \cdot 6 \mathrm{H}_{2} \mathrm{O}(35 \mathrm{mg}, 0.07 \mathrm{mmol})$, and $\mathrm{PPh}_{4} \mathrm{Br}(42 \mathrm{mg}, 0.10 \mathrm{mmol})$ were dissolved in water $(0.7 \mathrm{~mL})$ and $N, N$-dimethylformamide $(0.2 \mathrm{~mL})$. Yellow crystals of complex 2 were obtained within two days (29 mg, 59\% yield based on the acid). Anal. Calcd for $\mathrm{C}_{88} \mathrm{H}_{66} \mathrm{O}_{20} \mathrm{P}_{2} \mathrm{U}_{2}$ : C, 53.34; H, 3.36. Found: C, 53.13; H, 3.58\%.

$\left[\mathrm{UO}_{2}(\mathrm{ccn})(\text { bipy)}]_{2}\right.$ (3). 2-Carboxycinnamic acid (20 mg, $\left.0.10 \mathrm{mmol}\right), \mathrm{UO}_{2}\left(\mathrm{NO}_{3}\right)_{2} \cdot 6 \mathrm{H}_{2} \mathrm{O}$ (35 mg, $0.07 \mathrm{mmol})$, and 2,2'-bipyridine (32 mg, $0.20 \mathrm{mmol})$ were dissolved in water $(0.7 \mathrm{~mL})$ and $N, N$-dimethylformamide $(0.2 \mathrm{~mL})$. Yellow crystals of complex 3 were obtained in low yield within one week.

$\left[\mathrm{Ni}\left(\mathrm{R}, \mathrm{S}-\mathrm{Me}_{6} \mathrm{Cyclam}\right)\right]\left[\mathrm{UO}_{2}(\mathrm{ccn})(\mathrm{HCOO})\right]_{2}$ (4). 2-Carboxycinnamic acid (20 mg, 0.10 mmol), $\mathrm{UO}_{2}\left(\mathrm{NO}_{3}\right)_{2} \cdot 6 \mathrm{H}_{2} \mathrm{O}(35 \mathrm{mg}, 0.07 \mathrm{mmol})$, and $\left[\mathrm{Ni}\left(R, S-\mathrm{Me}_{6}\right.\right.$ cyclam $\left.)\left(\mathrm{NO}_{3}\right)_{2}\right](23 \mathrm{mg}, 0.05$ mmol) were dissolved in water $(0.9 \mathrm{~mL})$ and $N, N$-dimethylformamide $(0.2 \mathrm{~mL})$. Yellow crystals 
of complex 4 were obtained within one week (21 mg, 44\% yield based on U). Anal. Calcd for $\mathrm{C}_{38} \mathrm{H}_{50} \mathrm{~N}_{4} \mathrm{NiO}_{16} \mathrm{U}_{2}:$ C, 33.72; H, 3.72; N, 4.14. Found: C, 33.58; H, 3.94; N, 4.26\%.

[UO $\left.{ }_{2} \mathrm{Na}(1,2-p d d a)(\mathrm{OH})\right]$ (5). 1,2-Phenylenedioxydiacetic acid (23 mg, $\left.0.10 \mathrm{mmol}\right)$, $\mathrm{UO}_{2}\left(\mathrm{NO}_{3}\right)_{2} \cdot 6 \mathrm{H}_{2} \mathrm{O}(35 \mathrm{mg}, 0.07 \mathrm{mmol})$, and $\mathrm{NaNO}_{3}(17 \mathrm{mg}, 0.20 \mathrm{mmol})$ were dissolved in water $(0.7 \mathrm{~mL})$ and $N, N$-dimethylformamide $(0.2 \mathrm{~mL})$. Yellow crystals of complex 5 were obtained within three days (6 mg, 16\% yield based on $\mathrm{U}$ ). Anal. Calcd for $\mathrm{C}_{10} \mathrm{H}_{9} \mathrm{NaO}_{9} \mathrm{U}$ : C, 22.48; $\mathrm{H}$, 1.70. Found: C, 22.98; H, 1.79\%.

[(UO $\left.)_{2} \mathrm{Na}_{2}(1,2-p d d a)_{2}\left(\mathrm{C}_{2} \mathrm{O}_{4}\right)\right]$ (6). 1,2-Phenylenedioxydiacetic acid (23 mg, $\left.0.10 \mathrm{mmol}\right)$, $\mathrm{UO}_{2}\left(\mathrm{NO}_{3}\right)_{2} \cdot 6 \mathrm{H}_{2} \mathrm{O}(35 \mathrm{mg}, 0.07 \mathrm{mmol})$, and $\mathrm{NaNO}_{3}(17 \mathrm{mg}, 0.20 \mathrm{mmol})$ were dissolved in water $(0.7 \mathrm{~mL})$ and acetonitrile $(0.2 \mathrm{~mL})$. Yellow crystals of complex 6 were obtained in low yield within three days.

[UO $\left.2(1,2-p d d a)_{2} \mathrm{Ni}(c y c l a m)\right]$ (7). 1,2-Phenylenedioxydiacetic acid (23 mg, $\left.0.10 \mathrm{mmol}\right)$, $\mathrm{UO}_{2}\left(\mathrm{NO}_{3}\right)_{2} \cdot 6 \mathrm{H}_{2} \mathrm{O}(35 \mathrm{mg}, 0.07 \mathrm{mmol})$, and [Ni(cyclam) $\left.\left(\mathrm{NO}_{3}\right)_{2}\right](20 \mathrm{mg}, 0.05 \mathrm{mmol})$ were dissolved in water $(1.0 \mathrm{~mL})$ and $N, N$-dimethylformamide $(0.2 \mathrm{~mL})$. Pink-orange crystals of complex 7 were obtained in low yield within two days.

[UO $\left.2(1,3-p d d a)\left(\mathrm{H}_{2} \mathrm{O}\right)\right]$ (8). 1,3-Phenylenedioxydiacetic acid (23 mg, $\left.0.10 \mathrm{mmol}\right)$, $\mathrm{UO}_{2}\left(\mathrm{NO}_{3}\right)_{2} \cdot 6 \mathrm{H}_{2} \mathrm{O}(35 \mathrm{mg}, 0.07 \mathrm{mmol})$, and $\left[\mathrm{Ni}(\mathrm{cyclam})\left(\mathrm{NO}_{3}\right)_{2}\right](20 \mathrm{mg}, 0.05 \mathrm{mmol})$ were dissolved in water $(0.8 \mathrm{~mL})$ and acetonitrile $(0.2 \mathrm{~mL})$. Yellow crystals of complex 8 were obtained overnight (15 mg, 42\% yield based on $\mathrm{U}$ ). Anal. Calcd for $\mathrm{C}_{10} \mathrm{H}_{10} \mathrm{O}$. U: C, 23.45; $\mathrm{H}$, 1.97. Found: C, 23.70; H, 2.07\%. The same complex was also obtained in the presence of $\mathrm{PPh} 3 \mathrm{MeBr}$ (36 mg, $0.10 \mathrm{mmol}$ ) in place of the nickel(II) complex and $N, N$-dimethylformamide in place of acetonitrile, all other quantities being unchanged ( $11 \mathrm{mg}, 31 \%$ yield based on $U$ ).

Crystallography. The data were collected at 100(2) K on a Nonius Kappa-CCD area detector diffractometer ${ }^{13}$ using graphite-monochromated Mo K $\alpha$ radiation $(\lambda=0.71073 \AA)$. The 
crystals were introduced into glass capillaries with a protective coating of Paratone-N oil (Hampton Research). The unit cell parameters were determined from ten frames, then refined on all data. The data (combinations of $\varphi$ - and $\omega$-scans with a minimum redundancy of 4 for $90 \%$ of the reflections) were processed with HKL2000. ${ }^{14}$ Absorption effects were corrected empirically with the program SCALEPACK. ${ }^{14}$ The structures were solved by intrinsic phasing with SHELXT, ${ }^{15}$ expanded by subsequent difference Fourier synthesis and refined by fullmatrix least-squares on $F^{2}$ with SHELXL, ${ }^{16}$ using the SHELXle graphical user interface. ${ }^{17}$ All non-hydrogen atoms were refined with anisotropic displacement parameters. When present, the hydrogen atoms bound to oxygen and nitrogen atoms were retrieved from difference Fourier maps and refined with restraints on bond lengths when necessary, and with an isotropic displacement parameter equal to 1.2 times that of the parent atom (1.5 for $\mathrm{H}_{2} \mathrm{O}$ ). The carbonbound hydrogen atoms were introduced at calculated positions and were treated as riding atoms with an isotropic displacement parameter equal to 1.2 times that of the parent atom (1.5 for $\mathrm{CH}_{3}$, with optimized geometry). Crystal data and structure refinement parameters are given in Table 1. The molecular plots were drawn with ORTEP- $3,{ }^{18}$ and the polyhedral representations with VESTA. ${ }^{19}$ The topological analyses and nodal representations were made with ToposPro. $^{20}$

Luminescence Measurements. Emission spectra were recorded on solid samples using a Horiba-Jobin-Yvon IBH FL-322 Fluorolog 3 spectrometer equipped with a $450 \mathrm{~W}$ xenon arc lamp, double-grating excitation and emission monochromators $(2.1 \mathrm{~nm} / \mathrm{mm}$ of dispersion; 1200 grooves $/ \mathrm{mm}$ ) and a TBX-04 single photon-counting detector. The powdered compounds were pressed to the wall of a quartz tube, and the measurements were performed using the right-angle mode. Excitation spectra were recorded using the same apparatus and fixing the emission at $600 \mathrm{~nm}$. The quantum yield measurements were performed by using a Hamamatsu Quantaurus 
Table 1. Crystal Data and Structure Refinement Details

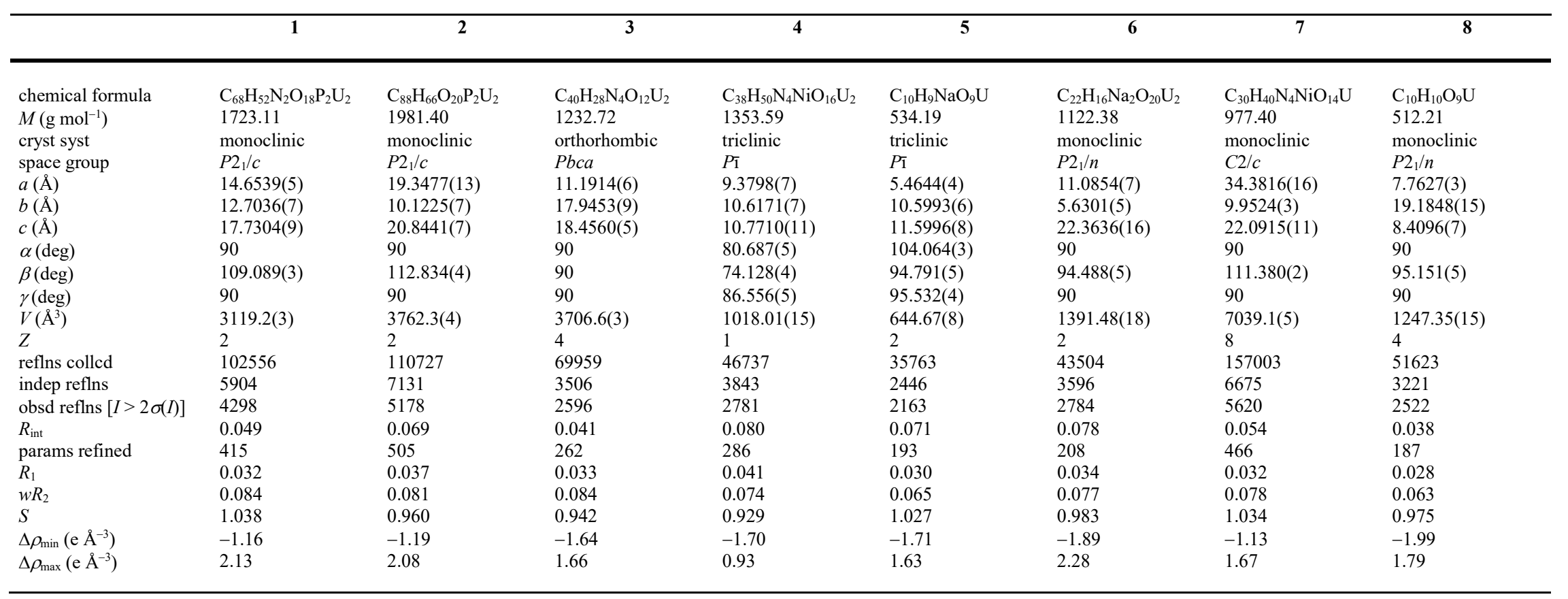


C11347 absolute photoluminescence quantum yield spectrometer and exciting the samples between 300 and $400 \mathrm{~nm}$. Time-resolved measurements were performed using the timecorrelated single-photon-counting PicoHarp300 on a PicoQuant FluoroTime 300 (PicoQuant GmbH, Germany), equipped with a PDL 820 laser pulse driver. A pulsed laser diode LDH-PC-405 $\left(\lambda_{\text {exc }}=440 \mathrm{~nm}\right)$ mounted at $90^{\circ}$ directly on the sample chamber was used to excite the sample. The photons were collected by a PMA-C-192 photomultiplier single-photon-counting detector. The data were acquired and analyzed by using the commercially available softwares EasyTau and FluoFit (PicoQuant GmbH, Germany).

\section{RESULTS AND DISCUSSION}

Synthesis. All complexes were synthesized under solvo-hydrothermal conditions, at a temperature of $140{ }^{\circ} \mathrm{C}$ (the crystals depositing at this temperature), with either acetonitrile (complexes 1, 6 and 8) or $N, N$-dimethylformamide (DMF, 2-5 and 7) as organic cosolvent. Only in complex 4 however does the solvent directly determine the nature of the final product since the formato coligands present probably arise from DMF hydrolysis. While the origin of the hydroxide anions in $\mathbf{5}$ is uncertain, hydrolysis of DMF should give rise to a change in solution $\mathrm{pH}$, providing yet another influence on solvothermal syntheses involving this solvent in addition to the frequently observed presence of formate and/or dimethylammonium ions. Oxalato coligands are found in complex $\mathbf{6}$, a quite frequent occurrence for complexes obtained under solvo-hydrothermal conditions, the formation mechanism having been investigated in detail in some cases. ${ }^{21,22}$ The exact origin of this oxalate in $\mathbf{6}$ is unknown but we have found oxalate formation to be prominent in systems involving crown ethers, ${ }^{23}$ so that it is possible that the source here was 1,2-pddaH 2 . The difference in synthetic procedures leading to 5 and $\mathbf{6}$ was simply the substitution of acetonitrile for DMF as cosolvent and hydrolysis of acetonitrile produces a weak acid/weak base mixture $\left(\mathrm{CH}_{3} \mathrm{CO}_{2} \mathrm{H} / \mathrm{NH}_{3}\right)$ with presumably rather similar 
influence on $\mathrm{pH}$ to that produced from DMF $\left(\mathrm{HCO}_{2} \mathrm{H} / \mathrm{HN}\left(\mathrm{CH}_{3}\right)_{2}\right)$; however, the rates would presumably be different and it appears that in the case of complex $\mathbf{6}$ a different reaction, an oxidation leading to oxalate, was more important. Complex 2 contains both the original ligand $\mathrm{ccn}^{2-}$ and the lactone 1,3-dihydro-3-oxo-1-isobenzofuranacetate (dibf ${ }^{-}$) formed in situ from cyclization of $\mathrm{ccn}^{2-}$, as previously reported, ${ }^{24}$ and found in several complexes. ${ }^{25,26}$ In all cases, the uranyl/dicarboxylate ligand ratio was $7: 10$ so as to favour the formation of an anionic species and the incorporation of structure-directing counterions, but this ratio is found in none of the complexes formed, the 1:1 ratio being observed instead in all cases but that of complex 7 for which it is 1:2. This however does not necessarily prevent the incorporation of counterions or additional metal ions due to the presence in several cases of anionic coligands, nitrato in $\mathbf{1}$, dibf in $\mathbf{2}$, formato in $\mathbf{4}$, hydroxo in $\mathbf{5}$, and oxalato in $\mathbf{6}$.

Crystal Structures. The four complexes involving the $\mathrm{ccn}^{2-}$ ligand, namely $\left[\mathrm{PPh}_{4}\right]_{2}\left[\mathrm{UO}_{2}(\mathrm{ccn})\left(\mathrm{NO}_{3}\right)\right]_{2} \quad(\mathbf{1}), \quad\left[\mathrm{PPh}_{4}\right]_{2}\left[\mathrm{UO}_{2}(\mathrm{ccn})(\mathrm{dibf})\right]_{2} \quad(\mathbf{2}), \quad\left[\mathrm{UO}_{2}(\mathrm{ccn})(\mathrm{bipy})\right]_{2} \quad$ (3), and $\left[\mathrm{Ni}\left(R, S-\mathrm{Me}_{6}\right.\right.$ cyclam $\left.)\right]\left[\mathrm{UO}_{2}(\mathrm{ccn})(\mathrm{HCOO})\right]_{2} \quad(4)$, present a common $\quad\left[\mathrm{UO}_{2}(\mathrm{ccn})\right]_{2}$ centrosymmetric, neutral core in which the uranyl cations are $\kappa^{2} O, O^{\prime}$-chelated by two carboxylate groups from the two ligands. Since this subunit is consistently obtained with very different coligands and counterions, it may be considered as possibly a quasi-permanent feature of uranyl complexes with this ligand, as are for example the similar dimeric, but generally dianionic moieties found in uranyl complexes with malate, citrate and related ligands. ${ }^{27,28}$ Note that despite the use of a ratio of reactants designed to generate tris(carboxylato)uranyl centres, an additional ligand is always found in place of a third carboxylate. This may simply be a consequence of differences in solubility but is also consistent with the $\left[\mathrm{UO}_{2}(\mathrm{ccn})\right]_{2}$ unit having an enhanced stability little influenced by the occupants of the residual coordination sites, so that solution concentrations are the primary influence on solubility. The $\mathrm{U}-\mathrm{O}$ bond lengths in the 
dimers are unexceptional [U-O(oxo) 1.762(4)-1.775(3) A, U-O(carboxylato) 2.422(3)2.523(5) $\AA$ ] , and the U $\cdots U$ separations are 7.8751(5), 7.9765(6), 8.1700(5) and 8.1564(8) $\AA$ for 1-4, respectively, indicating some slight adjustability of the 18 -membered ring. The $\mathrm{ccn}^{2-}$ anions are not far from being planar, consistent with a significant degree of delocalisation involving the alkene and phenyl ring components of the cinnamate units, with root mean square (rms) deviations of $0.17,0.22,0.03$, and $0.11 \AA$ for $\mathbf{1}-\mathbf{4}$, respectively, and they display a conformation and disposition of the carboxylate substituents as would be expected for 1,7naphthalenedicarboxylate. The dihedral angles between the $-\mathrm{COO}^{-}$groups and the aromatic ring do not exceed $30^{\circ}$ and are particularly small in $3\left[4.7(7)\right.$ and $2.5(9)^{\circ}$ for the groups containing $\mathrm{O} 3 / \mathrm{O} 4$ and $\mathrm{O} 5 / \mathrm{O} 6$, respectively]. The $\mathrm{C}_{\text {arom }}-\mathrm{C}_{\text {arom }}-\mathrm{C}=\mathrm{C}$ torsion angle, which indicates the tilting of the double bond out of the aromatic plane, is 158.5(4), 152.7(5), 175.7(6), and $162.5(7)^{\circ}$ in $\mathbf{1}-\mathbf{4}$, respectively, departure from planarity being here also the smallest in $\mathbf{3}$. The fact that the ligand closer to planarity is associated with the coligand (bipy) most tilted with respect to the uranyl equatorial plane (see below) may be significant, but the slight deviations from planarity observed in all cases may also be due to the interactions with the counterions, when present, or to packing effects. The $\left[\mathrm{UO}_{2}(\mathrm{ccn})\right]_{2}$ unit itself is also nearly planar, with only a slight offset of the two halves, the distance between one uranium atom and the mean plane defined by the other uranium atom and one attached ligand being 0.148(3), 0.291(4), 0.021(4) and $0.083(5) \AA$ for $\mathbf{1}-\mathbf{4}$, respectively. This dimeric subunit being a constant here, the structural variations between these four complexes arise from the coligands and/or counterions, although another constant worth noting is that in no case is the distance between carbon atoms of separate cinnamate alkene units lower than $6 \AA$, explaining the absence of any evidence for metal (uranyl) ion catalyzed cinnamate cyclodimerization (to a truxillic acid derivative), ${ }^{29}$ a reaction of a type known to occur in different uranyl ion complexes where the separation of $\mathrm{C}=\mathrm{C}$ units 
is $\sim 3.5 \AA .^{30}$ The charge of the chelating nitrate in $\mathbf{1}$ is balanced by that of $\mathrm{PPh}_{4}{ }^{+}$phosphonium cation (Figure 1). Analysis of short contacts with PLATON ${ }^{31}$ indicates the possible presence of

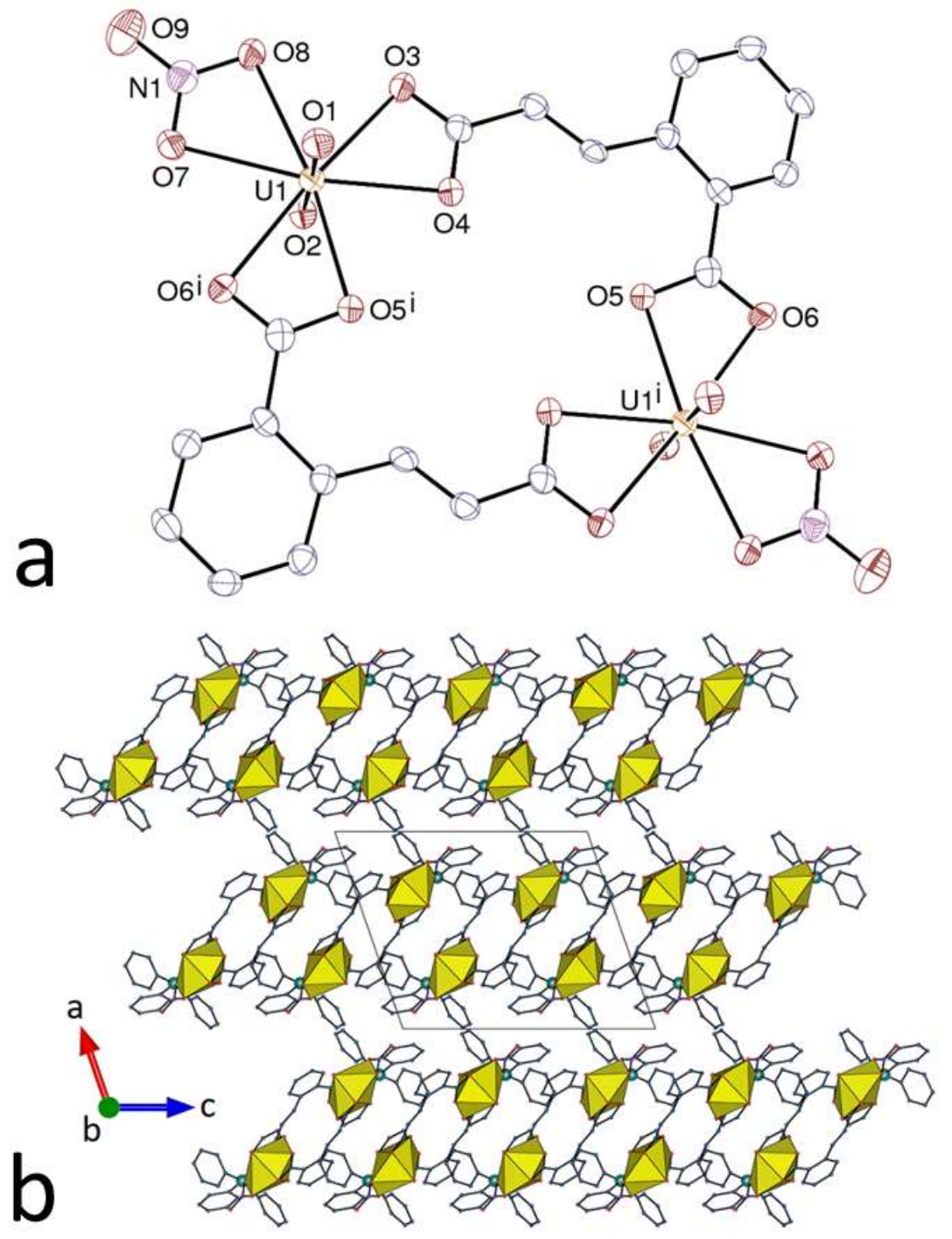

Figure 1. (a) View of compound 1. Displacement ellipsoids drawn at the 50\% probability level. Counterions and hydrogen atoms are omitted. Symmetry code: $\mathrm{i}=1-x, 2-y, 1-z$. (b) Packing with uranium coordination polyhedra colored yellow.

two parallel-displaced $\pi$-stacking interactions involving the aromatic ring of $\mathrm{ccn}^{2-}$ and two rings

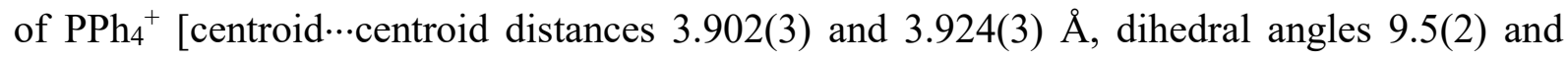
$\left.18.8(2)^{\circ}\right]$, as well as three $\mathrm{CH}-\pi$ interactions involving protons from either ligand or counterion and cation aromatic rings [H‥centroid 2.87-2.97 $\AA, \mathrm{C}-\mathrm{H} \cdots$ centroid $\left.130-145^{\circ}\right]$. Visualization 
of the Hirshfeld surface (HS) $)^{32}$ calculated with CrystalExplorer (version 3.1) ) $^{33}$ shows the latter to be significant, and evidences also the presence of $\mathrm{CH} \cdots \mathrm{O}$ hydrogen bonds ${ }^{34,35}$ involving $\mathrm{PPh}_{4}{ }^{+}$protons and carboxylato or nitrato acceptors $[\mathrm{C} \cdots \mathrm{O} 3.259(6)$ and 3.301(6) $\AA, \mathrm{C}-\mathrm{H} \cdots \mathrm{O}$ 139 and $131^{\circ}$ ], such $\mathrm{CH} \cdots \mathrm{O}$ interactions being very common in uranyl carboxylato complexes. The packing displays thick layers parallel to (100), with the dimeric anions tilted with respect to the layer plane, and the cations located on the two faces. Cations pertaining to adjacent layers are associated in pairs through a slighlty offset six-fold phenyl embrace, ${ }^{36}$ with however a rather large P...P separation of 7.229(3) $\AA$, while intralayer separations are larger than $9 \AA$. The Kitaigorodski packing index (KPI) calculated with PLATON, ${ }^{31}$ is 0.69 and no significant free space is present.

The subtleties of solvothermal synthesis are nicely revealed in that the substitution of DMF for $\mathrm{CH}_{3} \mathrm{CN}$ as cosolvent for an otherwise identical reaction mixture led to the isolation of complex 2 (Figure 2), containing cyclized carboxycinnamate, the chiral ligand 1,3-dihydro-3oxo-1-isobenzofuranacetate $\left(\operatorname{dibf}^{-}\right)$, as a replacement for the nitrate found in complex $\mathbf{1}$. The lactone unit of dibf ${ }^{-}$is apparently a weak coordinator, so once again the possibility of polymer formation by bridging of $\left[\mathrm{UO}_{2}(\mathrm{ccn})\right]_{2}$ units is thwarted. The planar bicyclic part of this anion is tilted by $74.20(8)^{\circ}$ from the average plane of the $\left[\mathrm{UO}_{2}(\mathrm{ccn})\right]_{2}$ unit. The anionic complexes are arranged in zigzag fashion into strongly corrugated, interdigitated layers parallel to (100), the counterions being located within the furrows. Here also, parallel-displaced $\pi$-stacking interactions involving the aromatic rings of $\mathrm{ccn}^{2-}$, dibf ${ }^{-}$, and $\mathrm{PPh}_{4}^{+}$may be present

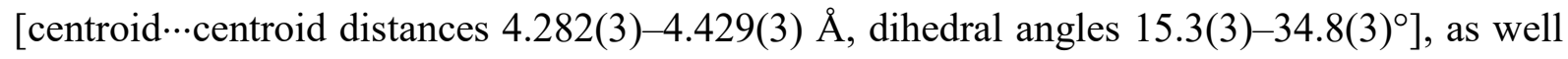
as one $\mathrm{CH}-\pi$ interaction involving a proton from the counterion and the $\mathrm{ccn}^{2-}$ aromatic ring $\left[\mathrm{H} \cdots\right.$ centroid $2.74 \AA, \mathrm{C}-\mathrm{H} \cdots$ centroid $\left.150^{\circ}\right]$, and several $\mathrm{CH} \cdots \mathrm{O}$ hydrogen bonds involving carboxylato, oxo and keto oxygen atoms $\left[\mathrm{C} \cdots \mathrm{O} 3.335(6)-3.344(7) \AA, \mathrm{C}-\mathrm{H} \cdots \mathrm{O} 137-150^{\circ}\right]$, the 

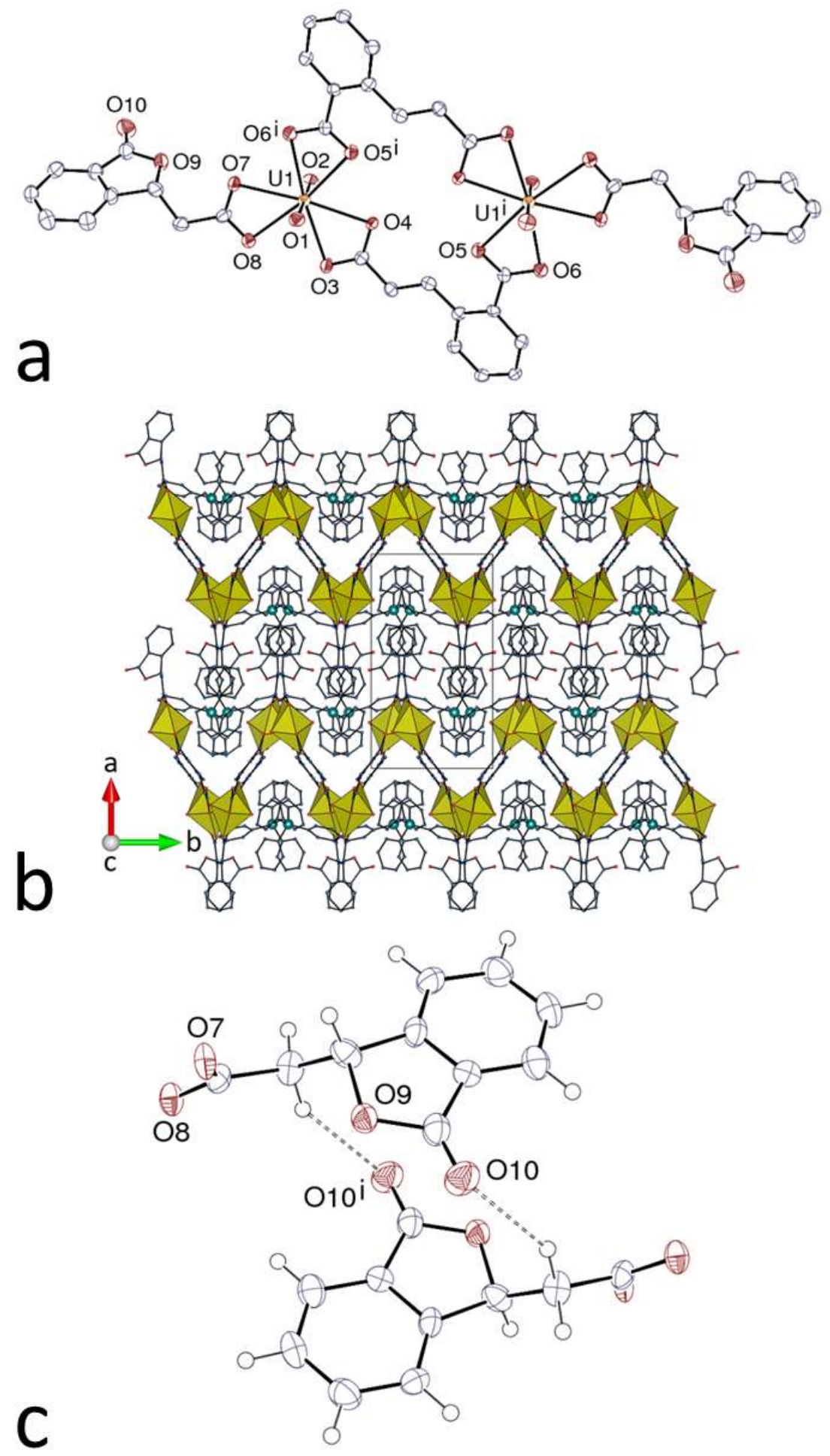

Figure 2. (a) View of compound 2. Displacement ellipsoids drawn at the $50 \%$ probability level. Counterions and hydrogen atoms are omitted. Symmetry code: $\mathrm{i}=2-x, 1-y, 2-z$. (b) Packing showing uranium coordination polyhedra. (c) Dimerization of dibf ligands through $\mathrm{CH}$ ‥O hydrogen bonding (dashed lines). Symmetry code: $\mathrm{i}$ $=1-x, 2-y, 2-z$. 
latter interactions being well apparent on the HS. Perhaps significantly in regard to the luminescence of complex 2 (see ahead), dibf $f^{-}$ligands form close pairs in which the aromatic rings are close to parallel (interplanar spacing $\sim 3.40 \AA$ ) but have little overlap in projection, the array seemingly being maintained by reciprocal $\mathrm{CH} \cdots \mathrm{O}$ interactions $\left(\mathrm{H} \cdots \mathrm{O} 10^{\mathrm{i}} 2.45 \AA\right.$; symmetry code: $\mathrm{i}=1-x, 2-y, 2-z$ ). All P..P distances here are larger than $10 \AA$, and no phenyl embrace is present. With a KPI of 0.70 , the packing is quite compact.

In contrast to $\mathbf{1}$ and $\mathbf{2 , 3}$ is a neutral complex, the chelating coligand here being bipy (Figure 3). That the core structure is maintained in what is now a neutral species is further evidence for its unusual stability, since in many other complexes of uranyl ion with moderately flexible dicarboxylates, complexation of diaza-aromatic ligands results in the formation of single strand polymers. As usual, bipy is tilted with respect to the mean plane defined by U1 and the four equatorial oxygen donors, the dihedral angle being $38.65(15)^{\circ}$, a value in the typical range. ${ }^{37}$ The uranium environment is thus chiral, the whole molecule being of course racemic. Parallel-displaced $\pi$-stacking interactions associate either two bipy molecules which form a slipped-stacked array parallel to [100] [centroid...centroid distance 3.886(4) A, dihedral angle $\left.25.6(3)^{\circ}\right]$, with the HS showing evidence of reciprocal $\mathrm{C} \cdots \mathrm{C}$ interactions exceeding dispersion, of two $\mathrm{ccn}^{2-}$ ligands $\left[3.877(3) \AA 0^{\circ}\right]$. A CH- $\pi$ interaction involves a $\mathrm{ccn}^{2-}$ proton and a bipy ring $\left[\mathrm{H} \cdots\right.$ centroid $2.65 \AA$, $\mathrm{C}-\mathrm{H} \cdots$ centroid $\left.164^{\circ}\right]$, and two $\mathrm{CH} \cdots \mathrm{O}$ hydrogen bonds link bipy protons and carboxylato groups $[\mathrm{C} \cdots \mathrm{O} 2.827(7)$ and 3.321(8) $\AA, \mathrm{C}-\mathrm{H} \cdots \mathrm{O} 124$ and $160^{\circ}$. The packing displays layers of parallel molecules perpendicular to [001], the orientation of the molecules being reversed from one sheet to the next (KPI 0.71). 


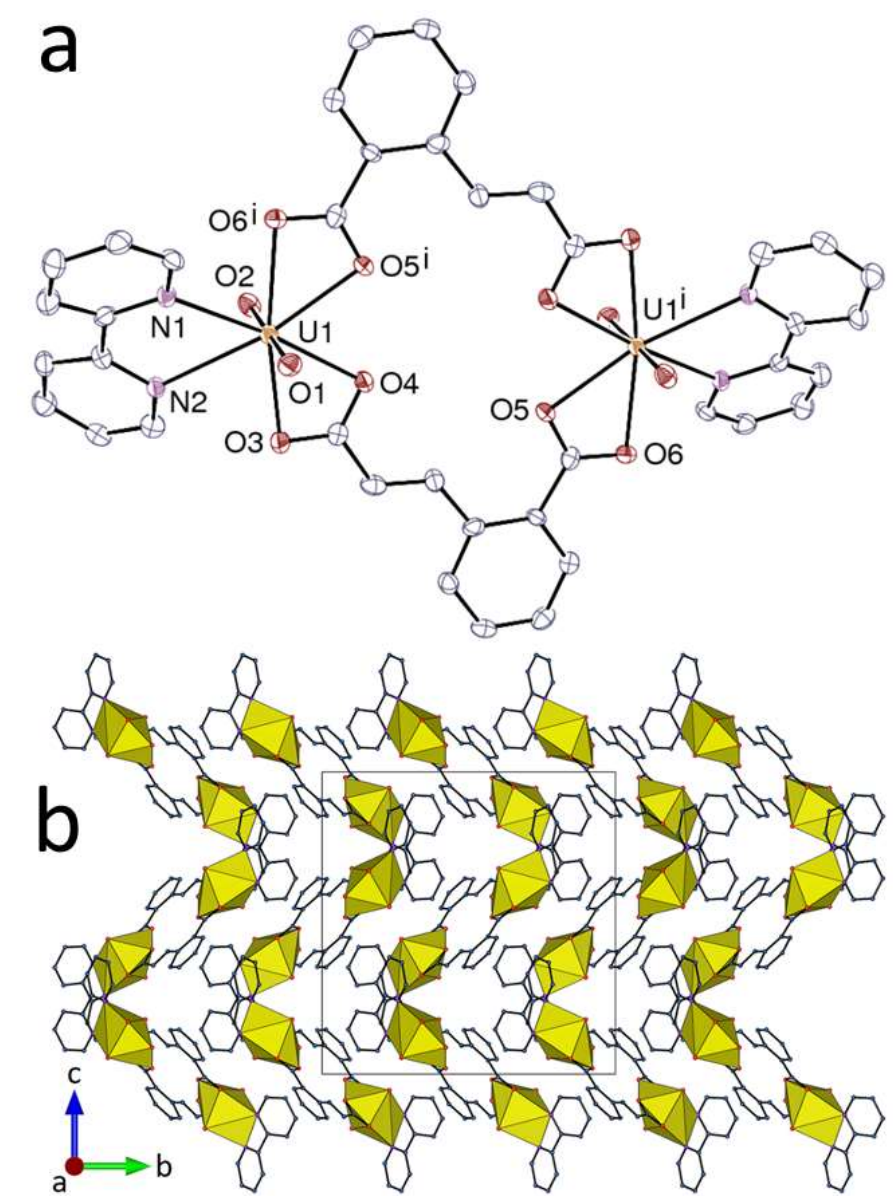

Figure 3. (a) View of compound 3. Displacement ellipsoids drawn at the 50\% probability level and hydrogen atoms are omitted. Symmetry codes: $\mathrm{i}=1-x, 1-y, 1-z$. (b) Packing showing uranium coordination polyhedra.

Complex 4 includes in situ-generated formate as third ligand in the uranyl equatorial plane, the charge being balanced by that of the centrosymmetric $\left[\mathrm{Ni}\left(R, S-\mathrm{Me}_{6} \text { cyclam }\right)\right]^{2+}$ counterion (Figure 4). This complex is unusual in that formate ligands, derived from DMF hydrolysis, block possible polymerization by adopting $\kappa^{2} O, O^{\prime}$ chelation as seen for nitrate in $\mathbf{1}$ and dibf in 2. Formate otherwise is most commonly seen to adopt $\mu_{2}-\kappa^{1} O: \kappa^{1} O^{\prime}$ bridging coordination in uranyl ion complexes ${ }^{3}$ (and also sometimes the simple $\kappa^{1} O$ mode). There is no direct coordination of nickel(II) to carboxylate groups, and the $\left[\mathrm{Ni}\left(\mathrm{Me}_{6} \mathrm{cyclam}_{\mathrm{C}}\right]^{2+}\right.$ counterion, known in other instances to interact with uranyl carboxylate complexes through axial coordination or $\mathrm{NH} \cdots \mathrm{O}$ bonding (or both), here appears to be involved exclusively in hydrogen bonding to both sides of the macrocyclic ligand plane. That the cation is not involved in 


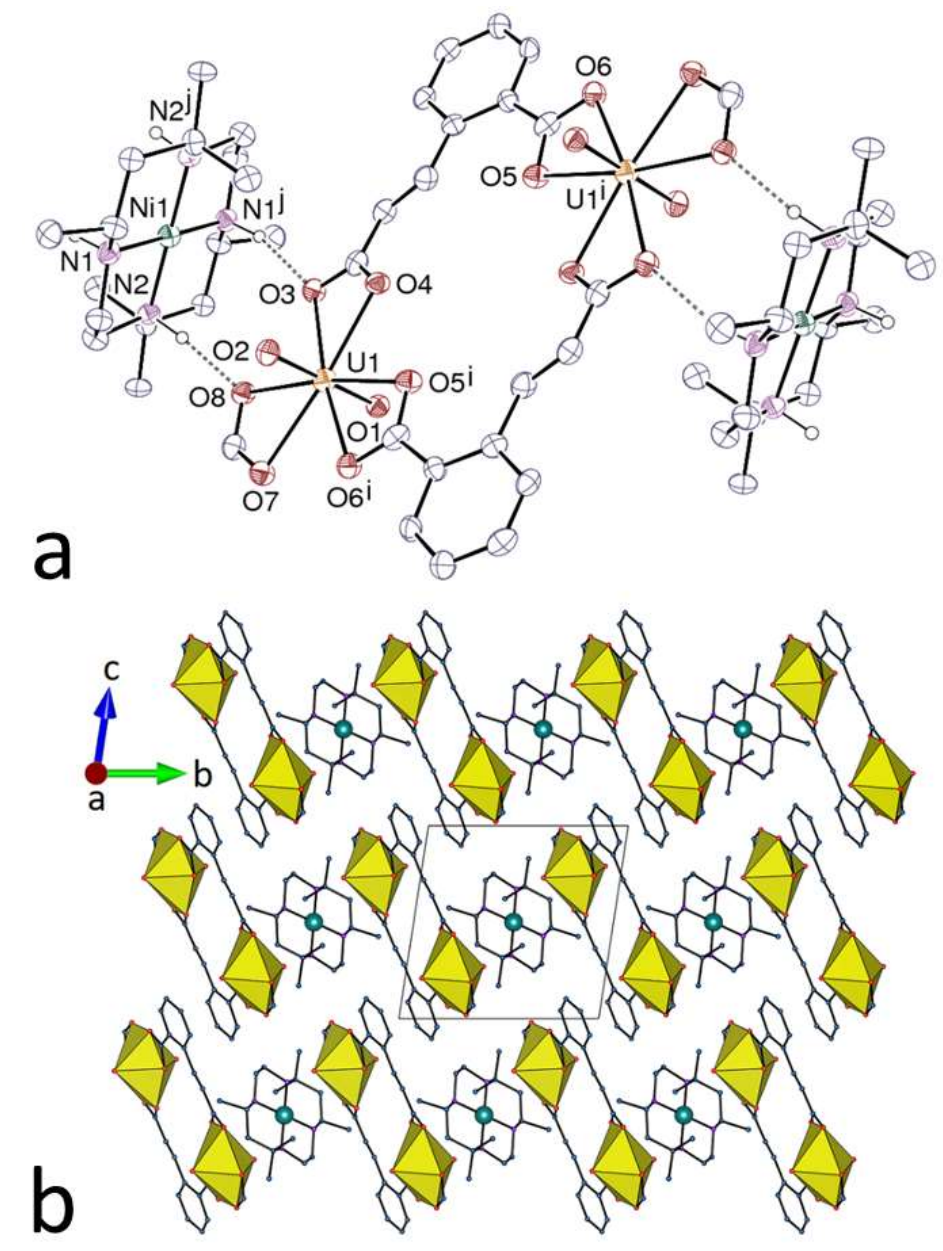

Figure 4. (a) View of compound 4. Displacement ellipsoids drawn at the $40 \%$ probability level. Carbon-bound hydrogen atoms are omitted and hydrogen bonds are shown as dashed lines. Symmetry codes: $\mathrm{i}=-x,-y, 1-z ; \mathrm{j}=$ $1-x, 1-y, 1-z$. (b) Packing with uranium coordination polyhedra colored yellow and nickel(II) ions shown as green spheres.

coordination to carboxylate groups may again be evidence of a particularly strong interaction in the $\left[\mathrm{UO}_{2}(\mathrm{cnn})\right]_{2}$ core. The protons of two adjacent $\mathrm{NH}$ groups in the macrocycle are bonded to two oxygen atoms in the coordination sphere of the same uranium centre $[\mathrm{N} \cdots \mathrm{O} 3.002(7)$ and 2.877(8) $\AA, \mathrm{N}-\mathrm{H} \cdots \mathrm{O} 163(6)$ and $\left.172(6)^{\circ}\right]$, thus forming a ring with the graph set descriptor ${ }^{38,39}$ $R_{2}^{2}(8)$. These bonds generate chains directed along [110], which are arranged into layers parallel to (001), the packing having a KPI of 0.74 . The layers are possibly linked to one another through parallel-displaced $\pi$-stacking interactions involving the $\mathrm{cen}^{2-}$ ligands [centroid $\cdots$ centroid distance 3.623(4) $\AA$, dihedral angle $0^{\circ}$ ], these interactions being sufficiently 
significant to be seen on the HS as reciprocal C $\cdots \mathrm{C}$ contacts $\left[\mathrm{C} 4 \cdots \mathrm{C} 6^{\mathrm{k}} 3.322(10) \AA\right.$; symmetry code: $\mathrm{k}=-x,-y, 2-z]$. Two $\mathrm{CH} \cdots \mathrm{O}$ hydrogen bonds between macrocycle protons and carboxylato groups are also present [C‥ 3.259(9) and 3.334(8) $\AA, \mathrm{C}-\mathrm{H} \cdots \mathrm{O} 130$ and $143^{\circ}$ ].

Two complexes have been obtained which involve the 1,2-pdda ${ }^{2-}$ ligand and both uranyl and $\mathrm{Na}^{+}$cations, $\left[\mathrm{UO}_{2} \mathrm{Na}(1,2-\mathrm{pdda})(\mathrm{OH})\right](\mathbf{5})$ and $\left[\left(\mathrm{UO}_{2}\right)_{2} \mathrm{Na}_{2}(1,2-\mathrm{pdda})_{2}\left(\mathrm{C}_{2} \mathrm{O}_{4}\right)\right](\mathbf{6})$. Although these two compounds have much in common, in particular the $\mathrm{U} / \mathrm{Na} / \mathrm{pdda}^{2-}$ stoichiometry, slightly different connectivities and the presence of different coligands, hydroxo and oxalato anions, respectively, result in the structures being different. As shown in Figures 5 and 6, the unique uranium atom in both $\mathbf{5}$ and $\mathbf{6}$ is chelated by one carboxylato group from 1,2-pdda ${ }^{2-}$ and is bound to one more donor from another 1,2- $\mathrm{pdda}^{2-}$ anion and either two bridging hydroxo ions or a chelating oxalato ion (five-membered chelate ring), the bond lengths being in the usual ranges [U-O(oxo) 1.770(4)-1.802(5) $\AA, \mathrm{U}-\mathrm{O}$ (carboxylato) 2.405(4)-2.476(4) $\AA$ for chelating groups and 2.309(3)/2.336(4) $\AA$ for the other groups, U-O(hydroxo) 2.325(5) and 2.342(5) $\AA$ ]. The uranium atom is thus in a pentagonal bipyramidal environment. As an atom used here to extend an acetate chain linked to an aromatic ring, oxygen brings the obvious possibility of acting as Lewis base, especially towards the alkali metal ions, and the addition of $\mathrm{NaNO}_{3}$ to the reaction mixture results in crystallization of a product reflecting this characteristic. Indeed, in both complexes, the unique sodium ion is bound to the two ether and two carboxylato groups of one 1,2-pdda ${ }^{2-}$ ligand, and one more carboxylato donor $\left(\mathrm{O} 4^{\mathrm{i}}\right)$, these four atoms defining a mean plane with an rms deviation of $0.039 \AA$ in $\mathbf{5}$ and $0.077 \AA$ and $\mathbf{6}$. This geometry is very close to that found in the complexes of $\mathrm{Na}^{+}$with $15-$ crown-5, and the $\mathrm{Na}-\mathrm{O}$ (carboxylato) [2.321(4)-2.491(5) $\AA]$ and $\mathrm{Na}-\mathrm{O}($ ether) $[2.525(5)-2.610(4) \AA]$ bond lengths in both complexes are comparable to the average $\mathrm{Na}-\mathrm{O}$ (ether) bond length of $2.470(10) \AA$ in the $\sim 180$ examples 

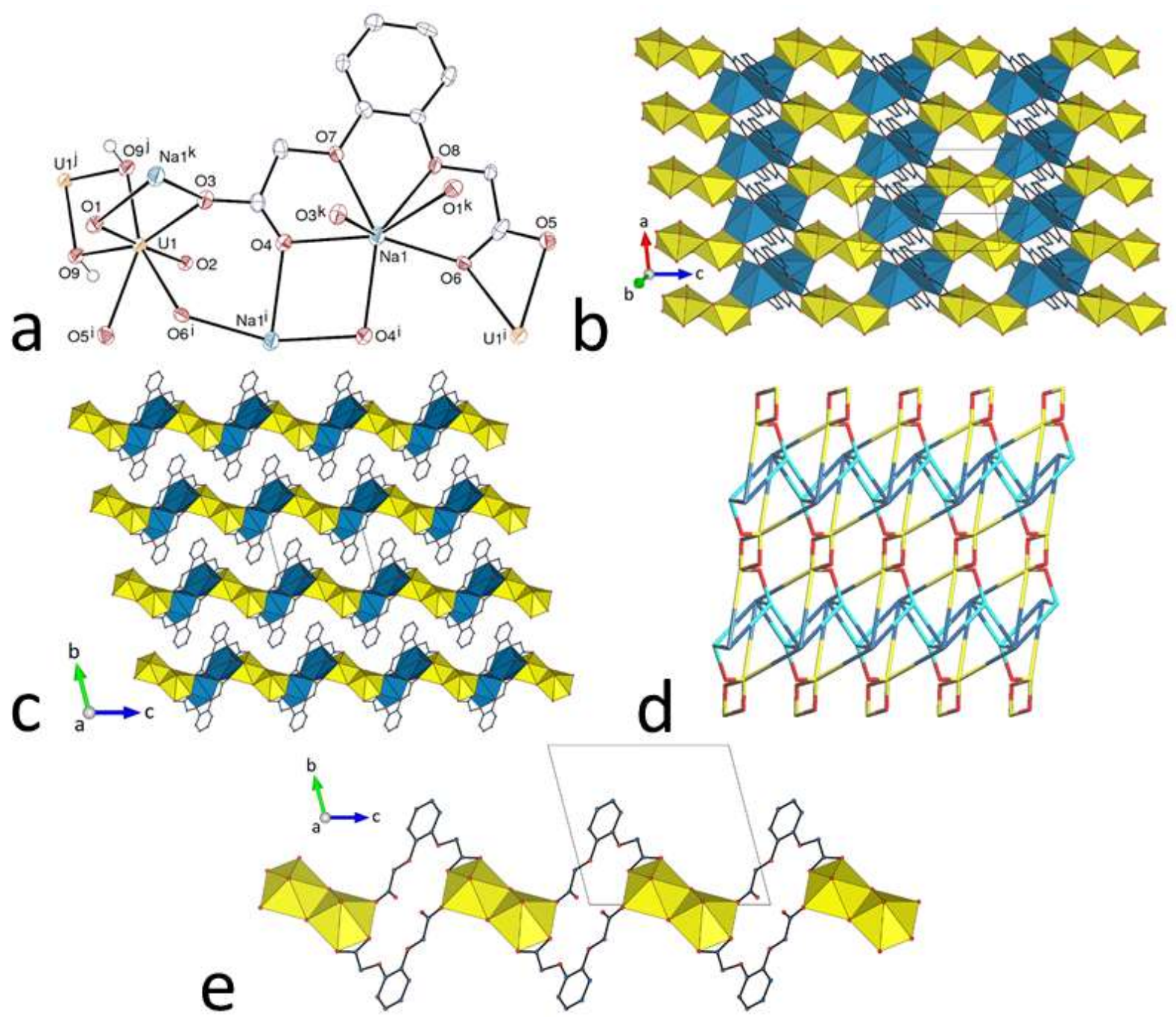

Figure 5. (a) View of compound 5. Displacement ellipsoids are drawn at the $50 \%$ probability level and hydrogen atoms are omitted. Symmetry codes: $\mathrm{i}=2-x, 2-y, 2-z ; \mathrm{j}=1-x, 2-y, 3-z ; \mathrm{k}=1-x, 2-y, 2-z$. (b) View of the 2D network. (c) View of the packing with layers viewed edge-on. Uranium coordination polyhedra are yellow and those of sodium blue. (d) Nodal representation of the 2D network (uranium nodes, yellow; sodium nodes, light blue; oxygen links, red; 1,2-pdda ${ }^{2-}$ nodes, dark blue; view down [010], with [100] horizontal). (e) View of the uranyl-only $1 \mathrm{D}$ subunit. 


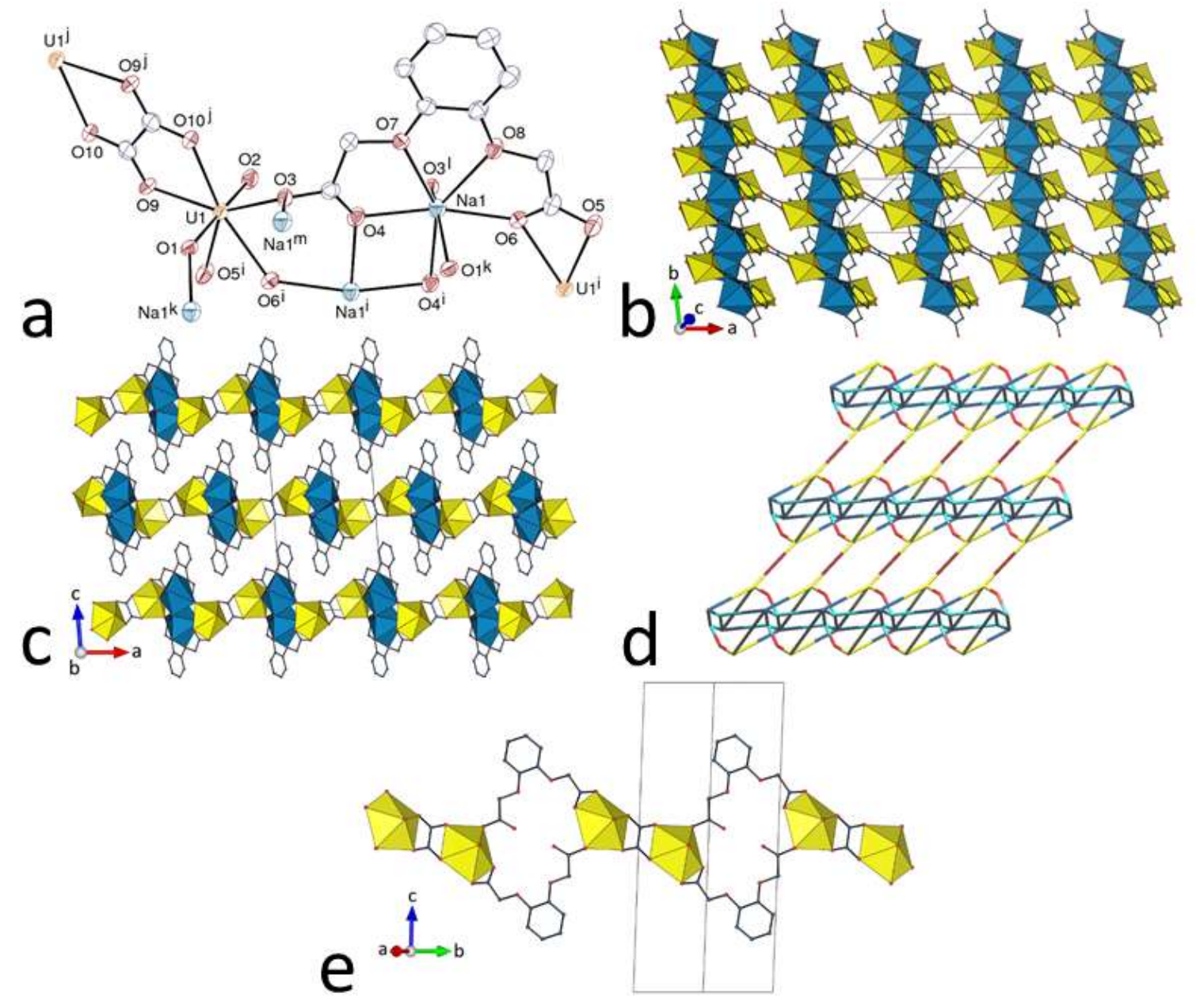

Figure 6. (a) View of compound 6. Displacement ellipsoids are drawn at the $50 \%$ probability level and hydrogen atoms are omitted. Symmetry codes: $\mathrm{i}=1-x,-y, 1-z ; \mathrm{j}=-x, 2-y, 1-z ; \mathrm{k}=1-x, 1-y, 1-z ; 1=x, y-1, z ; \mathrm{m}$ $=x, y+1, z$. (b) View of the $2 \mathrm{D}$ network. (c) View of the packing with layers viewed edge-on. Uranium coordination polyhedra are yellow and those of sodium blue. (d) Nodal representation of the 2D network (uranium nodes, yellow; sodium nodes, light blue; oxygen links, light red; 1,2-pdda ${ }^{2-}$ nodes, dark blue; oxalate links, dark red; [010] axis horizontal, [100] axis vertical). (e) View of the uranyl-only 1D subunit.

of 15 -crown-5 complexes reported in the CSD. Several other compounds have been reported in which $\mathrm{Na}^{+}$is bound to the four inward-directed oxygen atoms of the ligand, with a fifth donor providing a planar pentacoordinated array, ${ }^{40-43}$ while a complex in which it is bound to the eight donors from two orthogonal ligands is also known. ${ }^{44}$ The environment provided by the two convergent arms of 1,2-pdda ${ }^{2-}$ is thus particularly well suited to sodium complexation and, although lanthanoid cations frequently displace $\mathrm{Na}^{+}$from this site, ${ }^{43,45}$ the uranyl cation is 
clearly not a strong competitor of $\mathrm{Na}^{+}$for bonding to the ether groups, uranyl bonding to crown ethers having been found to be weak. ${ }^{46}$ Apart from this planar pentacoordinated set, the sodium cation in both $\mathbf{5}$ and $\mathbf{6}$ is bound to two more oxygen atoms, one carboxylato oxygen atom also bound to uranium, at a distance of 2.545(6) and 2.541(4) Å, respectively, and the uranyl oxo atom $\mathrm{O} 1$, the Na1-O1 bond lengths being however very different, at 2.786(5) $\AA$ in $\mathbf{5}$ and 2.384(4) $\AA$ in 6. A search of the CSD shows that $\mathrm{Na}-\mathrm{O}$ (uranyl oxo) bond lengths vary in a large range, from $\sim 2.1$ to $\sim 2.7 \AA$, with some tendency for the smaller bond lengths to be associated with the larger $\mathrm{U}=\mathrm{O}-\mathrm{Na}$ angles, which is verified here since the angles are $109.17(19)^{\circ}$ in $\mathbf{5}$ and $148.84(19)^{\circ}$ in $\mathbf{6}$. This bonding to sodium does not lead to any lengthening of the $\mathrm{U}=\mathrm{O}$ bond, and it is thus probably not very strong. Although the sodium centre is heptacoordinated in both compounds, the environment geometry is different since the two donors in addition to the five planar ones are on the same side of the plane in $\mathbf{5}$, and on either side in $\mathbf{6}$. The sodium environment can best be viewed as very distorted capped trigonal prismatic in $\mathbf{5}$ (with $\mathrm{O} 3^{\mathrm{k}} / \mathrm{O} 4 / \mathrm{O} 7$ and $\mathrm{O} 1^{\mathrm{k}} / \mathrm{O} 6 / \mathrm{O} 8$ defining the two faces, with a dihedral angle of $49.74(19)^{\circ}$, and $\mathrm{O} 4^{\mathrm{i}}$ in the capping position) and distorted pentagonal bipyramidal in $\mathbf{6}$. As a result, Na1 is more displaced from the $\mathrm{O}_{5}$ plane in 5 than in 6, with distances of $0.623(3)$ and $0.227(2) \AA$, respectively. The 1,2-pdda ${ }^{2-}$ ligand is bound to two uranyl and three sodium cations, the carboxylate groups adopting the $\mu_{4}-\kappa^{1} O: \kappa^{1} O: \kappa^{1} O^{\prime}: \kappa^{1} O^{\prime}$ and $\mu_{2}-\kappa^{2} O, O^{\prime}: \kappa^{1} O^{\prime}$ coordination modes. Diperiodic networks are formed in both cases, parallel to (010) in $\mathbf{5}$ and to (001) in $\mathbf{6}$, which contain monoperiodic uranyl-only subunits parallel to [10ī] in $\mathbf{5}$ and to [120] or [1-20] in 6 (Figures 5e and 6e). These chains of hydroxo- or oxalato-bridged uranyl dimers are such that the carboxylato oxygen atoms not bound to uranium, which are the fifth donors in the sodium $\mathrm{O}_{5}$ planar environment, face each other across the ring defined by the two 1,2-pdda ${ }^{2-}$ ligands. The $\left[\mathrm{UO}_{2}(1,2-\mathrm{pdda})\right]_{2}$ entities can thus be viewed as metallamacrocycles around pairs of $\mathrm{Na}^{+}$ions, but a single metallamacrocycle does not provide all the donor atoms bound to each 
of these cations. The coordination polyhedra of the two sodium atoms in the ring share a common edge, and each of them shares a common vertex with one uranium polyhedron of the same chain. Although the coordination mode of 1,2-pdda ${ }^{2-}$ to uranyl is the same as that found in $\left[\mathrm{UO}_{2}(1,2-\mathrm{pdda})\left(\mathrm{H}_{2} \mathrm{O}\right)\right],{ }^{11}$ the presence of the hydroxo and oxalato coligands and the occupation of the $\mathrm{O}_{4}$ site by sodium cations result in the chains being quite different. Further bonding of sodium to carboxylato and uranyl oxo groups from other chains results in diperiodic polymerization. In both compounds, the aromatic rings protrude on both sides of the thick layers and the packing is in "bump-to-hollow" fashion (KPIs 0.77 and 0.75 ). The hydroxo anion in 5 forms an intralayer hydrogen bond with the uranyl oxo atom not bound to $\mathrm{Na}^{+}[\mathrm{O} \cdots \mathrm{O} 2.905(7)$ $\left.\AA, \mathrm{O}-\mathrm{H} \cdots \mathrm{O} 164(7)^{\circ}\right]$. Interlayer parallel-displaced $\pi$-stacking interactions are possibly present in 5 [centroid $\cdots$ centroid distance $4.747(4) \AA$, dihedral angle $0^{\circ}$ ], while each aromatic ring may form two interlayer edge-to-face interactions in 6 [4.954(3) $\left.\AA, 70.2(3)^{\circ}\right]$. The HS reveals however mainly the usual $\mathrm{CH} \cdots \mathrm{O}$ hydrogen bonds.

The complex $\left[\mathrm{UO}_{2}(1,2-\text { pdda })_{2} \mathrm{Ni}(\right.$ cyclam $\left.)\right](7)$, represented in Figure 7, is very different from $\mathbf{5}$ and $\mathbf{6}$. The unique uranium atom is here chelated by one carboxylate group and bound to three more carboxylato oxygen atoms from three more ligands [U-O(oxo) 1.769(3) and 1.773(3) Å, U-O(carboxylato) 2.442(3) and 2.511(3) A for chelating groups and 2.258(3)2.369(3) $\AA$ for the other groups]. The two independent $\mathrm{Ni}^{\text {II }}$ cations, located on inversion centers, are bound to the four macrocyclic nitrogen atoms and two axial carboxylato donors, being thus in an octahedral environment [Ni-N 2.062(5)-2.068(4) $\AA$, Ni-O 2.091(3) and 2.112(3) $\AA]$, as often found when the $\mathrm{Ni}(\text { cyclam })^{2+}$ cation is associated with uranyl carboxylato complexes. ${ }^{12}$ This axial coordination results in partial detachment of one carboxylato donor of two potentially 


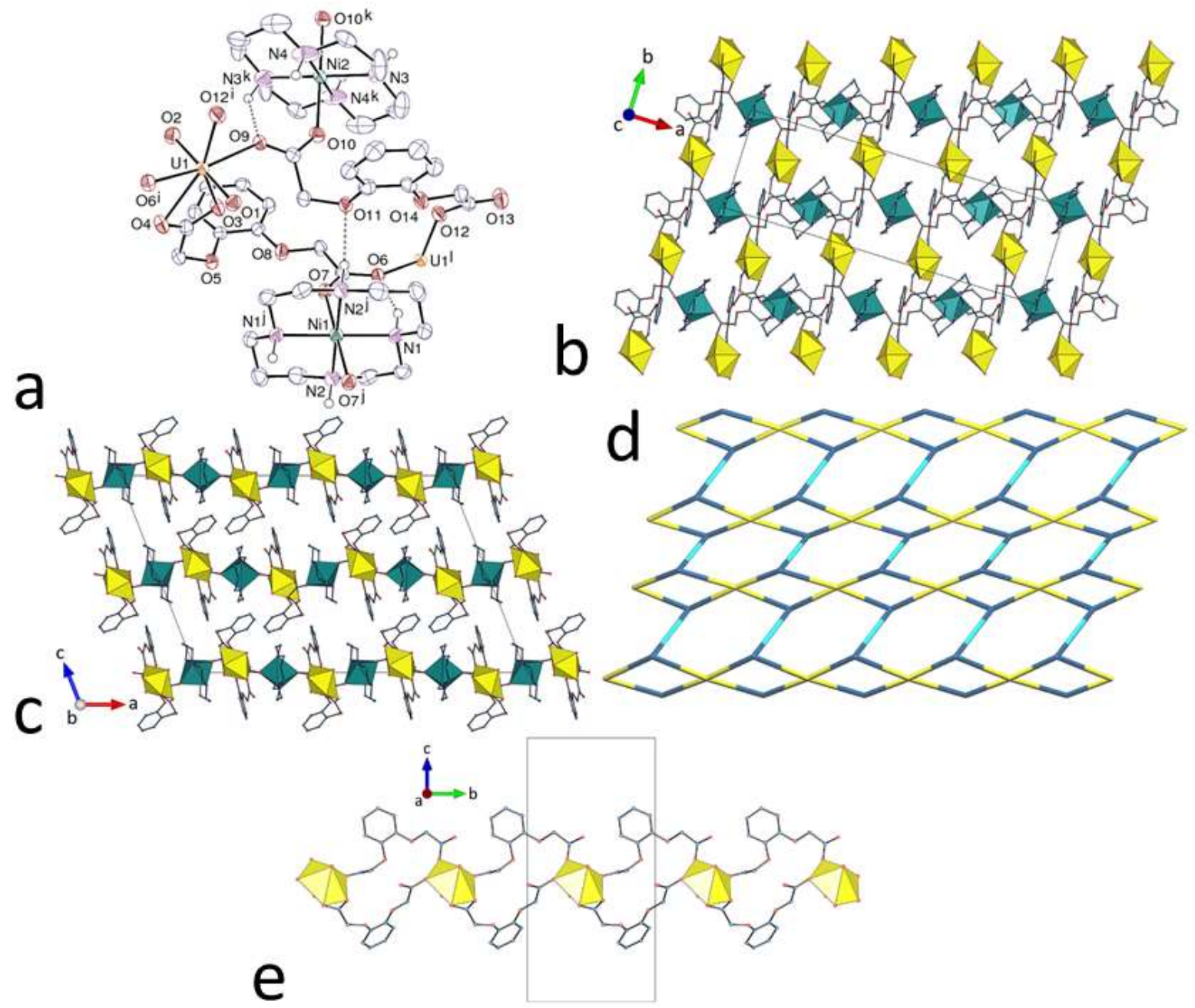

Figure 7. (a) View of compound 7. Displacement ellipsoids are drawn at the $50 \%$ probability level. Carbon-bound hydrogen atoms are omitted and hydrogen bonds are shown as dashed lines. Symmetry codes: $\mathrm{i}=x, y-1, z ; \mathrm{j}=1$ $-x, 1-y, 1-z ; \mathrm{k}=1 / 2-x, 1 / 2-y, 1-z ; 1=x, y+1, z$. (b) View of the $2 \mathrm{D}$ network. (c) View of the packing with layers viewed edge-on. Uranium coordination polyhedra are yellow and those of nickel(II) green. (d) Nodal representation of the 2D network (uranium nodes, yellow; nickel(II) links, light blue; 1,2-pdda ${ }^{2-}$ nodes, dark blue; [010] axis horizontal, [100] axis vertical). (e) View of the uranyl-only 1D subunit.

chelating carboxylate groups from uranium. As usual in such complexes, ${ }^{12}$ nickel(II) axial bonding is accompanied by hydrogen bonding of the macocyclic NH groups to carboxylate, and also here to one ether, oxygen atoms $[\mathrm{N} \cdots \mathrm{O}$ 2.981(5)-3.206(6) $\AA, \mathrm{N}-\mathrm{H} \cdots \mathrm{O}$ 130(5)$\left.170(4)^{\circ}\right]$. The two independent 1,2-pdda ${ }^{2-}$ ligands have different connectivities. Each has one carboxylate group bridging one uranium and one nickel atom in syn/anti $\mu_{2}-\kappa^{1} O: \kappa^{1} O^{\prime}$ mode, 
but the second carboxylate group is $\kappa^{2} O, O^{\prime}$-chelating in one ligand and monodentate in the other. More importantly, the ligands are not quasi-planar and do not define a convergent $\mathrm{O}_{4}$ array as in $\mathbf{5}$ and $\mathbf{6}$, but are clearly divergent, with one arm in the same conformation as in the other complexes, and the other pointing sideways (a conformation with both arms directed outward was previously found in $\left[\mathrm{H}_{2} \mathrm{DABCO}\right]\left[\left(\mathrm{UO}_{2}\right)_{2}(1,2-\mathrm{pdda})_{3}\right] \cdot 1.5 \mathrm{H}_{2} \mathrm{O},{ }^{11}$ with all carboxylate groups chelating). Uranyl and dicarboxylato ligands alone form monoperiodic chains running along [010] (Figure 7e), and further bridging by $\mathrm{Ni}^{\mathrm{II}}$ cations yields a diperiodic network parallel to (001) in which uranium atoms and 1,2-pdda ${ }^{2-}$ ligands are four- and threecoordinated (4-c and 3-c) nodes, respectively, and nickel atoms are simple links. The network has the point symbol $\left\{4.6^{2}\right\}_{2}\left\{4^{2} \cdot 6^{2} .8^{2}\right\}$ and the topological type $3,4 \mathrm{~L} 13$, previously found in homometallic uranyl ion complexes with 4,4'-biphenyldicarboxylate (with permutation of the metal and ligand roles), ${ }^{47}$ and in a complex with 1,3-adamantanediacetate and $\left[\mathrm{Ni}\left(\mathrm{Me}_{6} \text { cyclam }\right)\right]^{2+}$ bridges. ${ }^{48}$ Here also, the aromatic rings point on either side of the layers in an oblique way and the packing is compact (KPI 0.68), but no parallel-displaced $\pi$-stacking interaction is present. One $\mathrm{CH} \cdots \pi$ interaction may involve a cyclam methylenic proton $\left[\mathrm{H} \cdots\right.$ centroid $2.72 \AA, \mathrm{C}-\mathrm{H} \cdots$ centroid $\left.166^{\circ}\right]$, and $\mathrm{CH} \cdots \mathrm{O}$ hydrogen bonds link methylene groups from both ligands and oxo, carboxylato and ether oxygen atoms [C‥O 3.106(6)-3.521(6) $\AA$, $\left.\mathrm{C}-\mathrm{H} \cdots \mathrm{O} 113-160^{\circ}\right]$.

$\left[\mathrm{UO}_{2}(1,3-\mathrm{pdda})\left(\mathrm{H}_{2} \mathrm{O}\right)\right](\mathbf{8})$ is the only complex we could obtain in crystalline form with the 1,3 isomer of the $\mathrm{pdda}^{2-}$ ligand. The unique uranium atom is bound to four carboxylato oxygen donors from four different ligands and one water molecule, and it is thus in a pentagonal bipyramidal environment [U-O(oxo) $1.755(3)$ and 1.756(3) $\AA$, U-O(carboxylato) $2.354(3)-$ 2.396(3) $\AA$ ] (Figure 8). The two carboxylate groups of the 1,3-pdda ${ }^{2-}$ ligand are bridging in the syn/anti $\mu_{2}-\kappa^{1} O: \kappa^{1} O^{\prime}$ mode. One of the two arms (containing O6-O8) is nearly coplanar with 


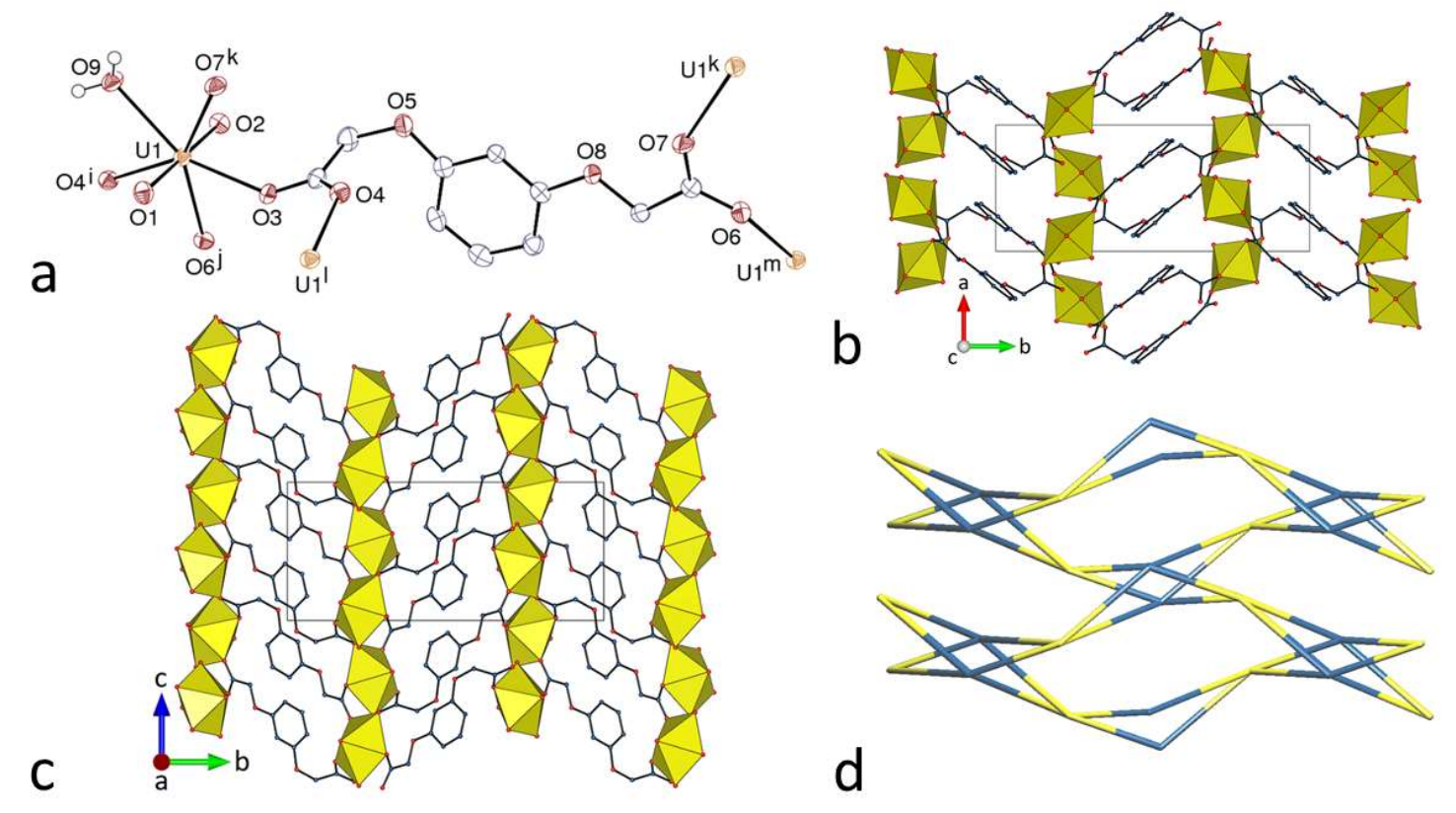

Figure 8. (a) View of compound 8. Displacement ellipsoids are drawn at the $50 \%$ probability level. Symmetry codes: $\mathrm{i}=x+1 / 2,3 / 2-y, z+1 / 2 ; \mathrm{j}=3 / 2-x, y+1 / 2,1 / 2-z ; \mathrm{k}=1-x, 1-y, 1-z ; 1=x-1 / 2,3 / 2-y, z-1 / 2 ; \mathrm{m}$ $=3 / 2-x, y-1 / 2,1 / 2-z$. (b) and (c) Two views of the framework showing uranium coordination polyhedra. (d) Nodal representation of the framework (uranium nodes, yellow; 1,3-pdda ${ }^{2-}$ nodes, dark blue; same orientation as in (b)).

the aromatic ring, while the other is buckled away so that the $-\mathrm{COO}^{-}$group is directed sideways. Both metal cation and anionic ligand are 4-c nodes in the triperiodic framework formed, which has the $\left\{4^{2} .8^{4}\right\}$ point symbol and the common pts topological type (however, the dicarboxylate ligand may alternatively be viewed as containing two 3-c nodes, the topological type thus becoming tfk). ${ }^{49,50}$ The pts topology (associated with three-fold interpenetration) was previously found in a uranyl ion complex with the tetrahedral ligand tetrakis(4carboxyphenyl)silicon. ${ }^{51}$ The geometry in the present case is however much less regular than in the latter example since three of the uranium centres bound to the 1,3-pdda ${ }^{2-}$ ligand are nearly coplanar with the centroid of the aromatic ring (deviations lower than $0.067 \AA$ ), while the fourth, bound in syn fashion to the buckled arm, is displaced by $3.79 \AA$ from this plane. The framework contains alternate layers of uranyl cations and organic ligands parallel to (010) and, 
when viewed down [001], the ligands appear to form narrow and elongated channels. The KPI of 0.73 indicates however that no solvent-accessible space is present. The coordinated water molecule forms hydrogen bonds with one carboxylato and one ether group [OO 2.684(4) and $2.819(5) \AA, \mathrm{O}-\mathrm{H} \cdots \mathrm{O} 156(5)$ and $\left.166(5)^{\circ}\right]$, and it thus has a possible influence on the ligand conformation and the disposition of its carboxylate groups. No parallel-displaced $\pi$-stacking interaction is present (centroid $\cdots$ centroid distances exceeding $5 \AA$ ), but two $\mathrm{CH} \cdots \pi$ interactions

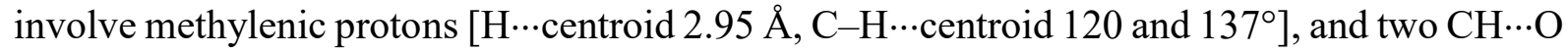
hydrogen bonds link aromatic or methylenic protons and oxo or carboxylato groups $[\mathrm{C} \cdots \mathrm{O}$ 3.386(5) and 3.350(5) $\AA, \mathrm{C}-\mathrm{H} \cdots \mathrm{O} 160$ and $144^{\circ}$ ], ensuring that ligand entities lie with their aromatic rings parallel (but offset) in planes separated by only $\sim 3.3 \AA$.

Luminescence properties. The emission spectra of complexes $\mathbf{1 , 2}, \mathbf{4}, \mathbf{5}$, and 8 in the solid state were recorded under excitation at $420 \mathrm{~nm}$, a sufficient quantity of pure sample being unavailable in the other cases, and they are shown in Figure 9. The spectra of complexes $\mathbf{1}$ and 5 display the usual fine structure associated with the vibronic progression corresponding to the $S_{11} \rightarrow S_{00}$ and $S_{10} \rightarrow S_{0 v}(v=0-4)$ electronic transitions..$^{52}$ The maxima of the $S_{10} \rightarrow S_{0 v}$ emission
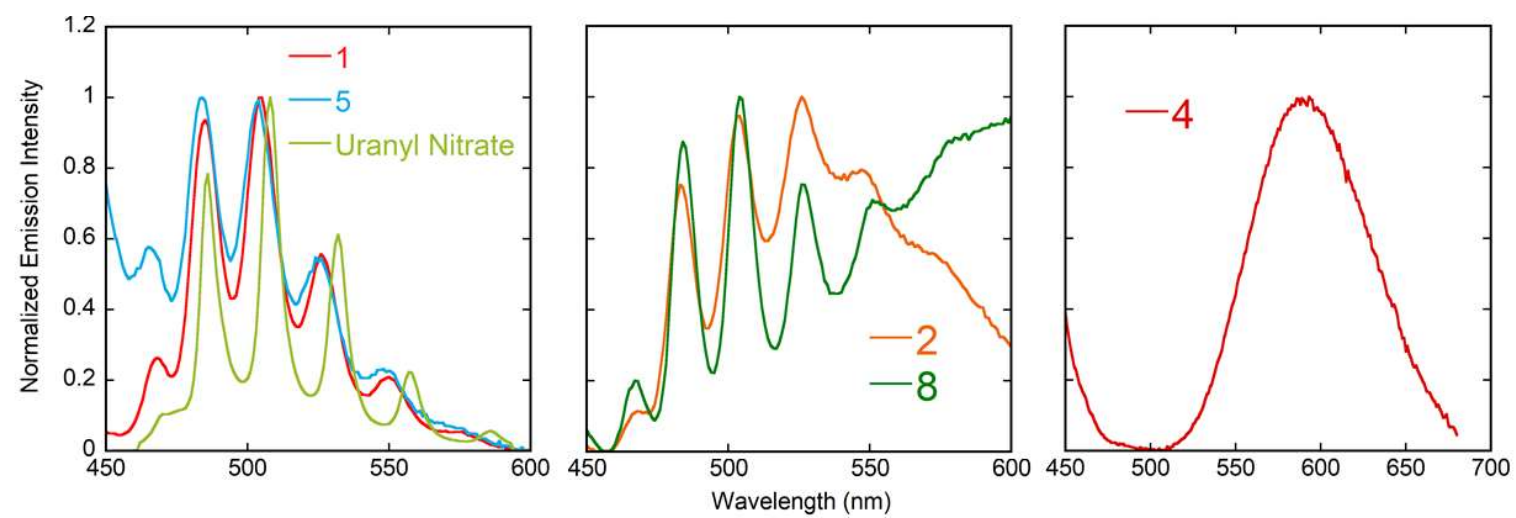

Figure 9. Emission spectra of complexes 1, 5 and $\mathrm{UO}_{2}\left(\mathrm{NO}_{3}\right)_{2} \cdot 6 \mathrm{H}_{2} \mathrm{O}$ (left), 2 and $\mathbf{8}$ (centre), and $\mathbf{4}$ (right) in the solid state at room temperature, under excitation at a wavelength of $420 \mathrm{~nm}$. 
peaks are at 485, 505, 526 and $550 \mathrm{~nm}$ for $\mathbf{1}$, and $484,504,525$ and $548 \mathrm{~nm}$ for $\mathbf{5}$, the former being in good agreement with, and the latter somewhat smaller than the values usual for $\mathrm{O}_{6}$ and $\mathrm{O}_{5}$ uranyl equatorial environments, respectively. ${ }^{53}$ The emission spectrum of uranyl nitrate hexahydrate, which displays maxima at 486, 508, 532, and $557 \mathrm{~nm}$, is given as a reference; although the position of its first peak is close to that for complexes $\mathbf{1}$ and $\mathbf{5}$, the separation increases with the wavelength, due to the vibronic splitting energy being slightly larger for uranyl nitrate (average $874 \mathrm{~cm}^{-1}$ ) than for the carboxylate complexes (average $812 \mathrm{~cm}^{-1}$ for $\mathbf{1}$ ). The emission spectra of complexes $\mathbf{2}$ and $\mathbf{8}$ appear anomalous in the sense that the vibronic emission bands typical of the uranyl ion are associated with a broad, long-wavelength emission with a form typical of that of an organic luminophore. The maxima positions of the $S_{10} \rightarrow S_{0 v}$ emission peaks are very close to those in $\mathbf{1}$ and $\mathbf{5}$, with a shift of $2 \mathrm{~nm}$ at most. The emission spectrum of complex 4 is even more anomalous since these uranium emission peaks are completely absent and only a broad emission band is seen. The ligand present in complex 2 resulting from cyclization of 2-carboxycinnamate is in fact an example of an organic luminophore known to form broad-band emissive complexes with $\mathrm{Zn}^{\mathrm{II}}$ and $\mathrm{Cd}^{\mathrm{II}}$ but with emission wavelengths much shorter than that of the broad bands in $\mathbf{2}, \mathbf{4}$ and $\mathbf{8} .^{24}$ Excitation spectra were recorded for complexes 2, 4 and $\mathbf{8}$ and are shown in Figure 10, where it is apparent

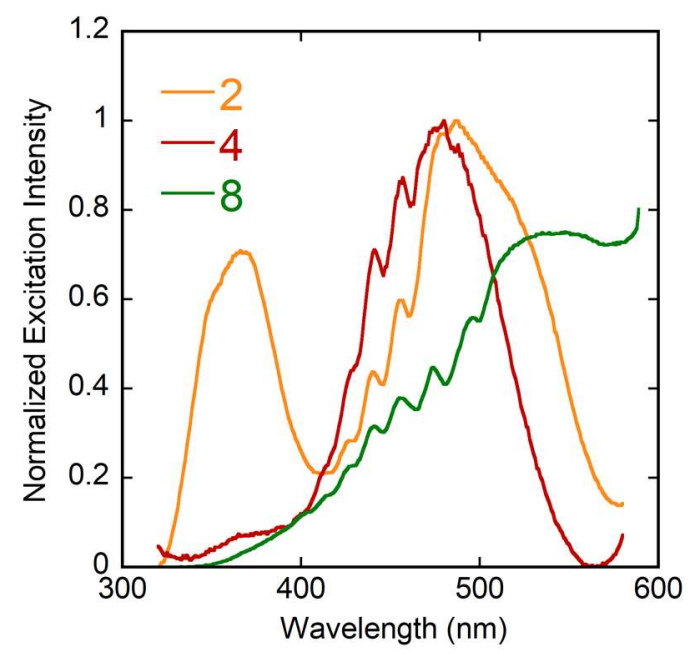

Figure 10. Excitation spectra of complexes 2, $\mathbf{4}$ and $\mathbf{8}$ in the solid state at room temperature. 
that a broad band lies at lower energy than the uranyl excited state manifold. Solid state excitedstate lifetimes were measured for complexes 2 and 4, fixing the emission wavelength at 600 $\mathrm{nm}$; both complexes feature a monoexponential decay, of 4 and $5 \mathrm{~ns}$, respectively, ruling out phosphorescence as the nature of emission, and therefore confirming that the emission is ligandcentered. In general, it is known ${ }^{54}$ that ligand-centred emission can occur from uranyl ion complexes but if this is so in the cases of $\mathbf{2 , 4}$ and $\mathbf{8}$, an explanation of the apparently exceptionally large Stokes shift is necessary. The structures provide some evidence of what this may be. The structure of $\mathbf{2}$ shows that both ligands lie in parallel planes but that the interplanar separation for the $\mathrm{ccn}^{2-}$ ligands is $\sim 10 \AA$, much greater than that considered to be indicative of any stacking interaction and very much greater than that known to favour photocatalyzed chemical reaction between alkene units in a related complex. ${ }^{30}$ The dibf ligands, however, lie in closer planes (see structure discussion above), in fact forming closest pairs in planes separated by $\sim 3.4 \AA$ and for which the Hirshfeld surface provides evidence for reciprocal $\mathrm{CH} \cdots \mathrm{O}$ interactions that would stabilise such a dimer (Figure 2c). Charge transfer interactions between aromatic entities aligned in such a manner are well known ${ }^{55}$ as a mechanism whereby colourless components give rise to a coloured aggregate, i.e. as a means of generating a low energy excited state, so that such interactions between dibf ${ }^{-}$ligands in 2 and 1,3-pdda ${ }^{2-}$ ligands in $\mathbf{8}$ (where close stacking is beyond pairwise) could be the origin of the broad, low energy emissions. An alternative explanation, also reflecting the close proximity of aromatic entities, would be the formation of excimer intermediates but it is not obvious how such possibilities could be distinguished in the solid state. In either case, it is significant that the shortest interplanar separation, that in complex $\mathbf{4}$, is associated with the most efficient quenching of uranyl ion emission (with also, in this case, a possible contribution of nickel(II) cations to quenching, as often observed with d block metal cations ${ }^{56-59}$ ). Solid-state photoluminescence 
quantum yields (PLQYs) have been measured for complexes $\mathbf{2}$ and $\mathbf{4}$, and they are very low, at about $1 \%$.

While, as noted above, ligand-centred emission from uranyl ion complexes is not unknown, ${ }^{54,60,61}$ it is rarely seen and thus it is unusual to find, as in the present study, three out of eight complexes which exhibit such behaviour. The excitation spectrum of complex 4, where uranyl ion emission is completely absent, provides clear evidence for a low energy excited state from which the emission has the characteristics of an organic luminophore. This ligandcentered nature of the emission is confirmed by the nanosecond-range excited state lifetimes in complexes 2 and 4. In our quite extensive investigations of uranyl ion complexes of polycarboxylate ligands, we have previously encountered but one similar case, where emission appeared to occur not from a directly bound ligand but from a counterion, $\left[\mathrm{Ni}(\mathrm{phen})_{3}\right]^{2+}{ }^{2}{ }^{62}$ Interestingly, re-examination of the relevant crystal structure shows that this is another instance where two aromatic entities [bipy ligands of adjacent cations with $\mathrm{Ni} \cdots \mathrm{Ni} 8.8147(12) \AA$ ] have a parallel, face-to-face orientation with an interplanar separation close to $3.3 \AA$. Although an alternative explanation of broad-band emission from uranyl ion complexes of 4,4'-bipyridine$N, N$-dioxide (bpdo) and hexacyanidometallates has been offered, ${ }^{63}$ it may be noted that these are species involving close pairs of bpdo ligands and that the only case where emission appears to be that typical of uranyl ion is the one where the pyridyl units in one ligand lie orthogonal to the nearest pyridine units of their adjacent ligand, whereas in instances where broad, low energy emissions appear, the arrays are much closer to face-to-face. This is obviously an issue requiring more detailed spectroscopic study.

\section{CONCLUSIONS}

The synthesis and crystal structure of eight uranyl ion complexes with three related ligands, 2carboxycinnamate $\left(\mathrm{cm}^{2-}\right)$ and the two isomers 1,2- and 1,3-phenylenedioxydiacetate (1,2- and 
1,3-pdda ${ }^{2-}$ ), have been reported. The uranyl complex unit which forms the basis of the crystal structures of the $\mathrm{ccn}^{2-}$ complexes $\mathbf{1 - 4}$ is somewhat unusual in the family of uranyl ion complexes of dicarboxylates in that it is a simple dimeric (dinuclear) species, whereas most such complexes are polymeric. It is also unusual in that its core form is maintained regardless of the nature of coligands or counter cations, at least in the four structures presently reported. Although $\mathrm{cen}^{2-}$ is a ligand able to depart from planarity, due to both rotation of the $-\mathrm{COO}^{-}$ groups and tilting of the double bond out of the aromatic plane, a flexibility which was exploited, for example, in the building of helical chains with $\mathrm{Cd}^{\mathrm{II}}$ cations, ${ }^{64}$ it assumes an essentially planar geometry in the present complexes $\mathbf{1 , 2}$ and $\mathbf{4}$ and a nearly perfect one in $\mathbf{3}$. This geometry and the separation and orientation of the two coordinating sites are perfectly adapted to the formation of the nearly planar, centrosymmetric $\left[\mathrm{UO}_{2}(\mathrm{ccn})\right]_{2}$ dimeric unit. The remaining coordination sites in the uranyl equatorial plane are occupied by various chelating coligands, the terminal nature of which prevents any periodicity increase. An interesting possibility would be to insert at these sites a large ditopic ligand with a sufficient separation of the two sites and a suitable shape to promote the formation of a closed, two-stranded species having two dimers as bases, as an enlarged and simpler version of the uranyl triple-stranded helicates obtained with long-chain $\alpha, \omega$-dicarboxylates, ${ }^{65}$ but attempts in this direction have not been successful up to now. Due to its mixed carboxylate/ether $\mathrm{O}_{4}$ central coordination site, 1,2pdda $^{2-}$ often encompasses a single cation and consequently adopts a planar shape. ${ }^{40}$ This is observed in complexes $\mathbf{5}$ and $\mathbf{6}$, in which a sodium(I) cation occupies this location, external coordination of uranyl, combined to uranyl oxo bonding to sodium, generating diperiodic networks. However, when the $\mathrm{O}_{4}$ site is unoccupied due to the low affinity of the uranyl ion for ether donors and unavailability of the other cations present, as in complex 7, 1,2-pdda ${ }^{2-}$ is able to adopt a distinctly non-planar shape resulting in the formation of a diperiodic network in which $[\mathrm{Ni}(\mathrm{cyclam})]^{2+}$ units bridge uranyl dicarboxylato chains. 1,3-pdda ${ }^{2-}$ does not suffer from 
the same constraints than the 1,2 isomer since it displays no $\mathrm{O}_{4}$ site, but its uranyl ion complexes seem to be even more averse to crystallization than those of the latter isomer. From inspection of the structures reported in the CSD, this ligand appears to be able to adopt several conformations, either planar, or with one $-\mathrm{COO}^{-}$group directed sideways, or with the two $\mathrm{COO}^{-}$groups directed toward the same or different sides of the aromatic ring. This flexibility of 1,3-pdda ${ }^{2-}$ and its ability to act as a convergent ligand are well illustrated, for example, in digallium complexes. ${ }^{66}$ In the homometallic, neutral uranyl complex 8, 1,3-pdda ${ }^{2-}$ adopts the conformation with one tilted arm, and the $\mu_{2}-\kappa^{1} O: \kappa^{1} O^{\prime}$-bridging coordination mode of both carboxylate groups allows formation of a triperiodic framework.

Two of the present complexes have usual uranyl emission spectra, with well-resolved vibronic fine structure, but three other complexes show also, and in one case only, ligandcentered emission. Although a plausible explanation of this somewhat unusual observation can be offered in terms of ligand-ligand interactions engendered within the crystal structures, it is not clear that this is of broader generality and further study of the phenomenon is warranted.

\section{ASSOCIATED CONTENT}

\section{Accession Codes}

CCDC 1963749-1963756 contain the supplementary crystallographic data for this paper. These data can be obtained free of charge via www.ccdc.cam.ac.uk/data_request/cif, or by emailing data_request@ccdc.cam.ac.uk, or by contacting The Cambridge Crystallographic Data Centre, 12 Union Road, Cambridge CB2 1EZ, UK; fax: +44 1223336033.

\section{AUTHOR INFORMATION}

\section{Corresponding Authors}

*E-mail: pierre.thuery@cea.fr. (P.T.) 
*E-mail: harrowfield@unistra.fr.(J.H.)

\section{ORCID}

Pierre Thuéry: 0000-0003-1683-570X

Youssef Atoini: 0000-0003-4851-3713

Jack Harrowfield: 0000-0003-4005-740X

\section{Notes}

The authors declare no competing financial interest.

\section{REFERENCES}

1. Wang, K. X.; Chen, J. S. Extended Structures and Physicochemical Properties of UranylOrganic Compounds. Acc. Chem. Res. 2011, 44, 531-540.

2. Andrews, M. B.; Cahill, C. L. Uranyl Bearing Hybrid Materials: Synthesis, Speciation, and Solid-State Structures. Chem. Rev. 2013, 113, 1121-1136.

3. Loiseau, T.; Mihalcea, I.; Henry, N.; Volkringer, C. The Crystal Chemistry of Uranium Carboxylates. Coord. Chem. Rev. 2014, 266-267, 69-109.

4. Su, J.; Chen, J. S. MOFs of Uranium and the Actinides. Struct. Bond. 2015, 163, 265-296.

5. Thuéry, P.; Harrowfield, J. Recent Advances in Structural Studies of Heterometallic UranylContaining Coordination Polymers and Polynuclear Closed Species. Dalton Trans. 2017, 46, $13660-13667$.

6. Thuéry, P.; Atoini, Y.; Harrowfield, J. Tubelike Uranyl-Phenylenediacetate Assemblies from Screening of Ligand Isomers and Structure-Directing Counterions. Inorg. Chem. 2019, 58, $6550-6564$. 
7. Thuéry, P.; Harrowfield, J. Modulation of the Structure and Properties of Uranyl Ion Coordination Polymers Derived from 1,3,5-Benzenetriacetate by Incorporation of $\mathrm{Ag}(\mathrm{I})$ or $\mathrm{Pb}(\mathrm{II})$. Inorg. Chem. 2016, 55, 6799-6816.

8. Thuéry, P.; Atoini, Y.; Harrowfield, J. Closed Uranyl-Dicarboxylate Oligomers: A Tetranuclear Metallatricycle with Uranyl Bridgeheads and 1,3-Adamantanediacetate Linkers. Inorg. Chem. 2018, 57, 7932-7939.

9. Groom, C. R.; Bruno, I. J.; Lightfoot, M. P.; Ward, S. C. The Cambridge Structural Database. Acta Crystallogr., Sect. B 2016, 72, 171-179.

10. Taylor, R.; Wood, P. A. A Million Crystal Structures: The Whole is Greater than the Sum of Its Parts. Chem. Rev. 2019, 119, 9427-9477.

11. Thuéry, P. Uranyl-Organic Assemblies with Acetate-Bearing Phenyl- and Cyclohexyl-Based Ligands. Cryst. Growth Des. 2011, 11, 347-355.

12. Thuéry, P.; Harrowfield, J. $[\mathrm{Ni}(\text { cyclam })]^{2+}$ and $\left[\mathrm{Ni}\left(R, S-\mathrm{Me}_{6} \text { cyclam }\right)\right]^{2+}$ as Linkers or Counterions In Uranyl-Organic Species with cis- and trans-1,2-Cyclohexanedicarboxylate Ligands. Cryst. Growth Des. 2018, 18, 5512-5520.

13. Hooft, R. W. W. COLLECT, Nonius BV: Delft, The Netherlands, 1998.

14. Otwinowski, Z.; Minor, W. Processing of X-Ray Diffraction Data Collected in Oscillation Mode. Methods Enzymol. 1997, 276, 307-326.

15. Sheldrick, G. M. SHELXT - Integrated Space-Group and Crystal-Structure Determination. Acta Crystallogr., Sect. A 2015, 71, 3-8.

16. Sheldrick, G. M. Crystal Structure Refinement with SHELXL. Acta Crystallogr., Sect. C 2015, $71,3-8$.

17. Hübschle, C. B.; Sheldrick, G. M.; Dittrich, B. ShelXle: a Qt Graphical User Interface for SHELXL. J. Appl. Crystallogr. 2011, 44, 1281-1284. 
18. Farrugia, L. J. WinGX and ORTEP for Windows: an Update. J. Appl. Crystallogr. 2012, 45, $849-854$.

19. Momma, K.; Izumi, F. VESTA 3 for Three-Dimensional Visualization of Crystal, Volumetric and Morphology Data. J. Appl. Crystallogr. 2011, 44, 1272-1276.

20. Blatov V. A.; Shevchenko, A. P.; Proserpio, D. M. Applied Topological Analysis of Crystal Structures with the Program Package ToposPro. Cryst. Growth Des. 2014, 14, 3576-3586.

21. Andrews, M. B.; Cahill, C. L. In Situ Oxalate Formation during Hydrothermal Synthesis of Uranyl Hybrid Materials. CrystEngComm 2011, 13, 7068-7078.

22. Knope, K. E.; Kimura, H.; Yasaka, Y.; Nakahara, M.; Andrews, M. B.; Cahill, C. L. Investigation of in Situ Oxalate Formation from 2,3-Pyrazinedicarboxylate under Hydrothermal Conditions Using Nuclear Magnetic Resonance Spectroscopy. Inorg. Chem. 2012, 51, 38833890.

23. Thuéry, P.; Atoini, Y.; Harrowfield, J. Crown Ethers and Their Alkali Metal Ion Complexes as Assembler Groups in Uranyl-Organic Coordination Polymers with cis-1,3-, cis-1,2-, and trans-1,2-Cyclohexanedicarboxylates. Cryst. Growth Des. 2018, 18, 3167-3177.

24. Murray, N. H.; LaDuca, R. L. Layered Dipyridylamide Coordination Polymers from in Situ Lactonization of 2-Carboxycinnamic Acid. Inorg. Chim. Acta 2014, 421, 145-151.

25. Sun, C.; Li, Y.; Li, W.; Dong, B. catena-Poly[[diaquabis[2-(3-oxo-1,3-dihydro-2-benzofuran1-yl)acetato- $\kappa O$ ]cobalt(II)]- $\mu-1,2-$ bis(pyridin-4-yl)ethane- $\left.\kappa^{2} N: N\right]$. Acta Crystallogr., Sect. E 2012, $68, \mathrm{~m} 1433$.

26. Shrode, A. D.; LaDuca, R. L. Diverse Interpenetration Schemes and Topologies in Cobalt Coordination Polymers Constructed from 2-Carboxycinnamic Acid and a Long-Spanning Dipyridylpiperazine Ligand. J. Mol. Struct. 2018, 1171, 726-732. 
27. Cole, E.; Flores, E.; Basile, M.; Jayasinghe, A.; de Groot, J.; Unruh, D. K.; Forbes, T. Z. Directing Dimensionality in Uranyl Malate and Copper Uranyl Malate Compounds. Polyhedron 2016, 114, 378-384.

28. Thuéry, P.; Harrowfield, J. Uranyl Ion Complexes with Chiral Malic and Citramalic, and Prochiral Citric and Tricarballylic Acids: Influence of Coligands and Additional Metal Cations. Eur. J. Inorg. Chem. 2018, 1016-1027.

29. Georgiev, I. G.; MacGillivray, L. R. Metal-Mediated Reactivity in the Solid State: from SelfAssembled Complexes to Metal-Organic Frameworks. Chem. Soc. Rev. 2007, 36,1239-1248.

30. Alcock, N. W.; de Meester, P.; Kemp, T. J. Solid-State Photochemistry. Part 1. Nature of the Stereocontrol in the Photodimerisation of Dibenzylideneacetone by $\mathrm{UO}_{2}{ }^{2+}$ ion: Crystal and Molecular Structure of trans-Dichlorobis(trans,trans-dibenzylideneacetone)dioxouranium(VI) and of its Acetic Acid Solvate. J. Chem. Soc., Perkin Trans 2 1979, 921-926.

31. Spek, A. L. Structure Validation in Chemical Crystallography. Acta Crystallogr., Sect. D 2009, $65,148-155$.

32. Spackman, M. A.; Jayatilaka, D. Hirshfeld Surface Analysis. CrystEngComm 2009, 11, 1932.

33. Wolff, S. K.; Grimwood, D. J.; McKinnon, J. J.; Turner, M. J.; Jayatilaka, D.; Spackman, M. A. CrystalExplorer; University of Western Australia: Crawley, Australia, 2012.

34. Taylor, R.; Kennard, O. Crystallographic Evidence for the Existence of $\mathrm{C}-\mathrm{H} \cdots \mathrm{O}, \mathrm{C}-\mathrm{H} \cdots \mathrm{N}$, and C-H‥Cl Hydrogen Bonds. J. Am. Chem. Soc. 1982, 104, 5063-5070.

35. Desiraju, G. R. The C-H‥O Hydrogen Bond: Structural Implications and Supramolecular Design. Acc. Chem. Res. 1996, 29, 441-449.

36. Dance, I.; Scudder, M. Supramolecular Motifs: Concerted Multiple Phenyl Embraces between $\mathrm{Ph}_{4} \mathrm{P}^{+}$Cations are Attractive and Ubiquitous. Chem. Eur. J. 1996, 2, 481-486. 
37. Thuéry, P.; Harrowfield, J. Anchoring Flexible Uranyl Dicarboxylate Chains through Stacking Interactions of Ancillary Ligands on Chiral U(VI) Centres. CrystEngComm 2016, 18, 39053918.

38. Etter, M. C.; MacDonald, J. C.; Bernstein, J. Graph-Set Analysis of Hydrogen-Bond Patterns in Organic Crystals. Acta Crystallogr., Sect. B 1990, 46, 256-262.

39. Bernstein, J.; Davis, R. E.; Shimoni, L.; Chang, N. L. Patterns in Hydrogen Bonding: Functionality and Graph Set Analysis in Crystals. Angew. Chem. Int. Ed. 1995, 34, 1555-1573.

40. Kennard, C. H. L.; Smith, G.; O’Reilly, E. J.; Reynolds, B. J.; Mak, T. C. W. MetalPhenoxyalkanoic Acid Interactions. Part 28. Crystal and Molecular Structures of the Sodium, Ammonium, and Magnesium Complexes of (o-Phenylenedioxy)diacetic Acid. J. Chem. Soc., Dalton Trans. 1988, 2357-2362.

41. Bott, R. C.; Sagatys, D. S.; Lynch, D. E.; Smith, G.; Kennard, C. H. L. The Preparation and Crystal Structure of Polymeric Anhydrous Sodium Hydrogen o-Phenylenedioxydiacetate. Aust. J. Chem. 1992, 45, 947-952.

42. Gawryszewska, P.; Ciunik, Z.; Kulesza, D. Structure and Optical Spectroscopy of Yb(III) Complex with o-Phenylenedioxydiacetic Acid. J. Mol. Struct. 2011, 988, 59-64.

43. Behrsing, T.; Deacon, G. B.; Junk, P. C.; Skelton, B. W.; Sobolev, A. N.; White, A. H. Hydrated Rare Earth Structural Networks Containing the Phenylene-1,2-dioxydiacetate (PDDA) Ligand. Z. Anorg. Allg. Chem. 2013, 639, 41-48.

44. Xu, L.; Gu, L. Y.; Yang, Y. Y.; Wang, B.; Kang, T. G. \{2-[2(Carboxymethoxy)phenoxy]acetato\}[2,2'-(o-phenylenedioxy)diacetic acid]sodium 4,4'Bipyridine Hemisolvate Monohydrate. Acta Crystallogr., Sect. E 2010, 66, m867.

45. Kerfoot, H. B.; Choppin, G. R.; Kistenmacher, T. J. Structure of Sodium Diaquobis(benzene1,2-dioxydiacetato)lanthanate(III) Tetrahydrate. Inorg. Chem. 1979, 18, 787-790. 
46. Thuéry, P.; Keller, N.; Lance, M.; Vigner, J. D.; Nierlich, M. Structural Investigation of Uranyl Complexes with Crown-Ethers, Azacrowns and Calixarenes. Structure of an Uranyl-Calixarene Bimetallic Inclusion Complex. New J. Chem. 1995, 19, 619-625.

47. Thuéry, P.; Harrowfield, J. Structural Variations in the Uranyl/4,4'-Biphenyldicarboxylate System. Rare Examples of 2D $\rightarrow$ 3D Polycatenated Uranyl-Organic Networks. Inorg. Chem. 2015, 54, 8093-8102.

48. Thuéry, P.; Atoini, Y.; Harrowfield, J. 1,3-Adamantanedicarboxylate and 1,3Adamantanediacetate as Uranyl Ion Linkers: Effect of Counterions, Solvents and Differences in Flexibility. Eur. J. Inorg. Chem. 2019, 4440-4449.

49. O’Keeffe, M.; Yaghi, O. M. Deconstructing the Crystal Structures of Metal-Organic Frameworks and Related Materials into Their Underlying Nets. Chem. Rev. 2012, 112, 675702.

50. Li, M.; Li, D.; O’Keeffe, M.; Yaghi, O. M. Topological Analysis of Metal-Organic Frameworks with Polytopic Linkers and/or Multiple Building Units and the Minimal Transitivity Principle. Chem. Rev. 2014, 114, 1343-1370.

51. Liu, C.; Chen, F. Y.; Tian, H. R.; Ai, J.; Yang, W.; Pan, Q. J.; Sun, Z. M. Interpenetrated Uranyl-Organic Frameworks with bor and pts Topology: Structure, Spectroscopy, and Computation. Inorg. Chem. 2017, 56, 14147-14156.

52. Brachmann, A.; Geipel, G.; Bernhard, G.; Nitsche, H. Study of Uranyl(VI) Malonate Complexation by Time Resolved Laser-Induced Fluorescence Spectroscopy (TRLFS). Radiochim. Acta 2002, 90, 147-153.

53. Thuéry, P.; Harrowfield, J. Structural Consequences of 1,4-Cyclohexanedicarboxylate Cis/Trans Isomerism in Uranyl Ion Complexes: From Molecular Species to 2D and 3D Entangled Nets. Inorg. Chem. 2017, 56, 13464-13481. 
54. Natrajan, L. S. Developments in the Photophysics and Photochemistry of Actinide Ions and their Coordination Compounds. Coord. Chem. Rev. 2012, 256, 1583-1603.

55. Wright, J. D. Molecular Crystals, Cambridge University Press, Cambridge, UK, 1987, pp. 1718 and $39-43$.

56. Burrows, H. D.; Formosinho, S. J.; Miguel, M. da G.; Pinto Coelho, F. Quenching of the Luminescent State of the Uranyl Ion $\left(\mathrm{UO}_{2}{ }^{2+}\right)$ by Metal Ions -Evidence for an Electron Transfer Mechanism. J. Chem. Soc., Faraday Trans. 1 1976, 72, 163-171.

57. Kerr, A. T.; Cahill, C. L. Postsynthetic Rearrangement/Metalation as a Route to Bimetallic Uranyl Coordination Polymers: Syntheses, Structures, and Luminescence. Cryst. Growth Des. 2014, 14, 1914-1921.

58. Kerr, A. T.; Cahill, C. L. CuPYDC Metalloligands and Postsynthetic Rearrangement/Metalation as Routes to Bimetallic Uranyl Containing Hybrid Materials: Syntheses, Structures, and Fluorescence. Cryst. Growth Des. 2014, 14, 4094-4103.

59. Gomez, G. E.; Ridenour, J. A.; Byrne, N. M.; Shevchenko, A. P.; Cahill, C. L. Novel Heterometallic Uranyl-Transition Metal Materials: Structure, Topology, and Solid State Photoluminescence Properties. Inorg. Chem. 2019, 58, 7243-7254.

60. Vaughn, A. E.; Bassil, D. B.; Barnes, C. L.; Tucker, S. A.; Duval, P. B. Contrasting Solvent and Capping Ligand Effects Directing the Photochemistry of Uranyl(VI) Schiff Base Complexes. J. Am. Chem. Soc. 2006, 128, 10656-10657.

61. Hardwick, H. C.; Royal, D. S.; Helliwell, M.; Pope, S. J. A.; Ashton, L.; Goodacre, R.; Sharrad, C. A. Structural, Spectroscopic and Redox Properties of Uranyl Complexes with a Maleonitrile Containing Ligand. Dalton Trans. 2011, 40, 5939-5952.

62. Thuéry, P.; Rivière, E.; Harrowfield, J. Uranyl and Uranyl-3d Block Cation Complexes with 1,3-Adamantanedicarboxylate: Crystal Structures, Luminescence and Magnetic Properties. Inorg. Chem. 2015, 54, 2838-2850. 
63. Chorazy, S.; Zakrzewski, J. J.; Reczyński, M.; Sieklucka, B. Multi-Colour Uranyl Emission Efficiently Tuned by Hexacyanidometallates within Hybrid Coordination Frameworks. Chem. Commun. 2019, 55, 3057-3060.

64. Li, F.; Ma, Z.; Wang, Y. L.; Cao, R.; Bi, W. H.; Li, X. Exploring the Synthesis of Infinite Helical Chains with 2-Carboxycinnamic Acid. CrystEngComm 2005, 7, 569-574.

65. Thuéry, P.; Harrowfield, J. A New Form of Triple-Stranded Helicate Found in Uranyl Complexes of Aliphatic $\alpha, \omega$-Dicarboxylates. Inorg. Chem. 2015, 54, 10539-10541.

66. Uhl, W.; Stefaniak, C.; Layh, M. Ga-Ga Bonds as Key Building Blocks for the Formation of Supramolecular Entities - Unusual Macrocyclic Tetra- and Octagallium Compounds. Eur. J. Inorg. Chem. 2017, 2270-2278. 
For Table of Contents Use Only

\section{Functionalized Aromatic Dicarboxylate Ligands in Uranyl-Organic Assemblies: the Cases of Carboxycinnamate and 1,2-/1,3-Phenylenedioxydiacetate}

Pierre Thuéry, Youssef Atoini and Jack Harrowfield

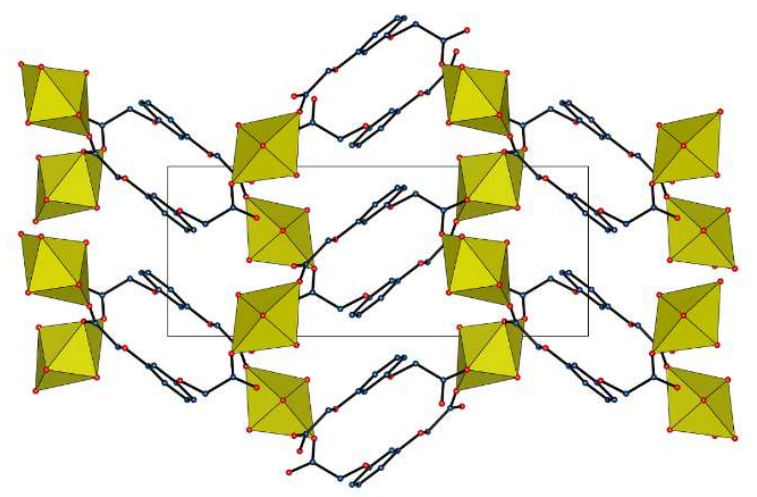

2-Carboxycinnamate is a ligand with a marked tendency to planarity, which, in the presence of terminal coligands, consistently forms quasi-planar, dinuclear, dimeric units with the uranyl ion. In contrast, the isomeric 1,2- and 1,3-phenylenedioxydiacetates can adopt either planar or nonplanar conformations, leading to various di- and triperiodic assemblies. 